\title{
Prenatal and Early Postnatal Odorant Exposure Heightens Odor-Evoked Mitral Cell Responses in the Mouse Olfactory Bulb
}

\author{
(1D)Annie Liu, ${ }^{1,2,4}$ and Nathaniel N. Urban ${ }^{1,2,3,4}$
}

DOI:http://dx.doi.org/10.1523/ENEURO.0129-17.2017

${ }^{1}$ Center for Neuroscience at the University of Pittsburgh, University of Pittsburgh, Pittsburgh, PA, ${ }^{2}$ Center for the Neural Basis of Cognition, Pittsburgh, PA, ${ }^{3}$ Department of Biological Sciences, Carnegie Mellon University, Pittsburgh, PA, and ${ }^{4}$ Department of Neurobiology, University of Pittsburgh, Pittsburgh, PA

\begin{abstract}
Early sensory experience shapes the anatomy and function of sensory circuits. In the mouse olfactory bulb (OB), prenatal and early postnatal odorant exposure through odorized food (food/odorant pairing) not only increases the volume of activated glomeruli but also increases the number of mitral and tufted cells (M/TCs) connected to activated glomeruli. Given the importance of M/TCs in OB output and in mediating lateral inhibitory networks, increasing the number of M/TCs connected to a single glomerulus may significantly change odorant representation by increasing the total output of that glomerulus and/or by increasing the strength of lateral inhibition mediated by cells connected to the affected glomerulus. Here, we seek to understand the functional impact of this long-term odorant exposure paradigm on the population activity of mitral cells (MCs). We use viral expression of GCaMP6s to examine odor-evoked responses of MCs following prenatal and early postnatal odorant exposure to two dissimilar odorants, methyl salicylate (MS) and hexanal, which are both strong activators of glomeruli on the dorsal OB surface. Previous work suggests that odor familiarity may decrease odor-evoked MC response in rodents. However, we find that early food-based odorant exposure significantly changes MC responses in an unexpected way, resulting in broad increases in the amplitude, number, and reliability of excitatory MC responses across the dorsal $\mathrm{OB}$.
\end{abstract}

Key words: mitral cells; olfaction; olfactory bulb; plasticity

\section{Significance Statement}

The structure and output of the olfactory bulb (OB) circuit can be modified by odor experience throughout both development and adulthood. The highly specific organization of this system lends itself to detailed analyses of how experience can shape the architecture of sensory system responses. Previous work demonstrated that prenatal and early postnatal odorant exposure using a food-based paradigm increased the number of primary projection neurons connected to activated glomeruli. This increase may have significant effects on odorant representation and $\mathrm{OB}$ output. In this study, we focus on understanding how this odorant exposure paradigm impacts the odor-evoked responses of one population of primary OB output neurons, the mitral cells (MCs).

\section{Introduction}

The olfactory bulb (OB) has a stereotyped structure, the organization of which is dictated in part by odorant receptor (OR) identity (Ressler et al., 1994; Vassar et al., 1994;

Received April 12, 2017; accepted August 14, 2017; First published September 25, 2017.

The authors declare no competing financial interests.

Author contributions: A.L. and N.N.U. designed research; A.L. performed research; A.L. analyzed data; A.L. and N.N.U. wrote the paper.
Potter et al., 2001; Bozza et al., 2002; Treloar et al., 2002; Feinstein and Mombaerts, 2004; Komiyama and Luo, 2006). Olfactory sensory neurons (OSNs) send axons to

\footnotetext{
This work was supported by National Institute on Deafness and Other Communication Disorders Grants RO1DC011184 (to N.N.U.) and F30DC015161 (to A.L.) and by the Pennsylvania Department of Health Commonwealth Universal Research Enhancement Program (N.N.U.).

Acknowledgements: We thank Claire Cheetham for helpful comments and technical advice and Greg LaRocca for technical help.
} 
the OB, where axons from OSNs expressing the same OR converge into roughly spherical structures called glomeruli. Each glomerulus contains dendrites of a cohort of juxtaglomerular and primary projection neurons, the mitral and tufted cells (M/TCs), together, these make up a glomerular module, the basic odor-coding unit of the OB. Each glomerular module thus has a genetic identity based on OR expression as well as a cohort of activating odorant ligands for the corresponding OR.

This OR identity-based organization facilitates the investigation of how specific olfactory experiences change the OB. Anatomic studies demonstrate that the OB circuitry is highly plastic and subject to experience-dependent structural changes throughout both development and adulthood. Odor exposure using a number of different conditioning paradigms increases glomerular volume (Woo et al., 1987; Todrank et al., 2011; Dias and Ressler, 2014; Morrison et al., 2015). Combined prenatal and early postnatal odor exposure increases both glomerular volume and associated M/TC number (Todrank et al., 2011; Liu et al., 2016), while early aversive conditioning accelerates the rate of glomerular convergence (Kerr and Belluscio, 2006). Early postnatal passive odorant exposure has also been shown to decrease cell turnover in the glomerular and granule cell layers (Woo et al., 2006). In adult mice, aversive odorant conditioning increases OSN number and glomerular volume, these changes are reversed following the extinguishing of the learned aversive response (Morrison et al., 2015). These studies use different conditioning or exposure paradigms, yet they all have significant effects of OB circuitry, suggesting that several distinct mechanisms may influence the development and maintenance of $\mathrm{OB}$ structure. These large modifications to $\mathrm{OB}$ circuitry may in turn have significant effects on the representation and processing of odorants in the $\mathrm{OB}$.

Odor-evoked activity in the rodent $\mathrm{OB}$ is also influenced by odorant experience and exposure. Rodents demonstrate both acute and chronic reductions in the amplitude and probability of odor-evoked excitatory M/TC responses following repeated odor presentation (Chaudhury et al., 2010; Kato et al., 2012). In rats, early postnatal odorant exposure paired with positive somatosensory stimuli decreases the number of excitatory M/TC responses elicited by the learned odorant while leaving responses to unassociated odorants unchanged (Wilson et al., 1985, 1987). However, the relationship between experience-dependent anatomic circuit changes and odor-evoked activity in the OB is not well understood, as there is significant interstudy variation in the delivery, context, and timing of odorant exposure or conditioning.

Here, we use an odor exposure paradigm with a previously characterized anatomic correlate to understand

Correspondence should be addressed to Nathaniel N. Urban, Department of Neurobiology, University of Pittsburgh, E1440 BSTWR, 200 Lothrop Street, Pittsburgh, PA 15213, E-mail: nurban@pitt.edu.

DOI:http://dx.doi.org/10.1523/ENEURO.0129-17.2017

Copyright (C) 2017 Liu and Urban

This is an open-access article distributed under the terms of the Creative Commons Attribution 4.0 International license, which permits unrestricted use, distribution and reproduction in any medium provided that the original work is properly attributed. how odor representation may be affected by these changes in circuit structure. Todrank et al. (2011) and Liu et al. (2016) found that food-based prenatal and early postnatal odorant exposure increases glomerulus volume and the number of M/TCs corresponding to activated glomerular modules, while increasing behavioral preference for the odor that was paired with food. Given that a single odorant activates multiple glomeruli across the $\mathrm{OB}$, these observed changes in glomerular volume and $\mathrm{M} / \mathrm{TC}$ number could be generalized to many glomeruli and thus have a large distributed impact on odor representation in the $\mathrm{OB}$. We investigate how early chronic food-based odorant exposure, a paradigm known to change $\mathrm{OB}$ anatomy, impacts the odor-evoked responses of MCs in the dorsal mouse OB. Surprisingly, we find that odor-evoked calcium transients in MCs are broadly enhanced rather than reduced in this food pairing paradigm.

\section{Materials and Methods}

All animal procedures were performed in accordance with the University of Pittsburgh animal care committee's regulations.

\section{Animals and surgical methods}

All experiments were done in male and female M72IRES-tauGFP mice. Imaging was done on adult mice, at five to eight weeks of age. During all surgical procedures, animals were anesthetized using a ketamine/xylazine mixture, provided analgesia using carprofen injections, and maintained at $37^{\circ} \mathrm{C}$ body temperature. Expression of GCaMP6s was achieved through injection of $1 \mu \mathrm{l}$ of AAVhsyn-GCaMP6s $\sim 250 \mu \mathrm{m}$ underneath the pial surface in the dorsal posterior OB surface. Animals were allowed to recover for two weeks, after which they were used for acute in vivo anesthetized imaging experiments. For acute imaging, a 2-mm diameter craniotomy was made over the dorsal posterior $\mathrm{OB}$ and covered with low melting point agarose. A coverslip was secured over the craniotomy using dental cement to minimize z-plane movement. Imaging was done in anesthetized animals maintained at $37^{\circ} \mathrm{C}$ body temperature.

\section{Odorant exposure}

Prenatal and early postnatal odorant exposure was performed on M72-IRES-tauGFP mice as detailed in Todrank et al. (2011) and Liu et al. (2016). Two qualitatively distinct odorants were used for odor-exposure groups. Methyl salicylate (MS) has a wintergreen scent and activates both olfactory and trigeminal responses, while hexanal has a green grass scent and activates only olfactory receptors. Both odorants are strong activators of glomeruli on the dorsal $\mathrm{OB}$ surface in rats and mice, with different but overlapping activation areas (Glomerular Activity Response Archive, Michael Leon, gara.bio.uci.edu/index.jsp; Wachowiak and Cohen, 2001, 2003). We exposed animals to these odors by adding these odors to the food provided to these animals, as described previously (Todrank et al., 2011; Liu et al., 2016), a manipulation that results in altered preference for the conditioned food and altered glomerular module structure. 
Food was mixed with either MS (mint) or hexanal (1\% by volume) and dried under a fume hood for $3 \mathrm{~d}$. Breeding pairs were fed with either control, mint-scented, or hexanal-scented food for the duration of gestation and nursing (Fig. 1A). Litters were subsequently weaned onto and continuously fed with either control, mint-scented, or hexanal-scented food until acute calcium imaging experiments. Both male and female mice were used for imaging. Breeding pairs were weighed regularly to ensure that odorized food did not interfere with food consumption. Odorant-exposed litters were not of substantially different weights from control litters.

\section{Stimulus delivery}

Each trial consisted of 4-s room air, 1-s odorized air, and 25-s room air. Each odorant was presented four times in pseudorandom stimulus order and with intertrial interval length of at least $1 \mathrm{~min}$. Stimuli consisted of 14 odorants: eight odorants diluted in mineral oil at different concentrations [1\%: isoamyl acetate (IAA), hexanal, MS, ethyl butyrate (EB), propionic acid (PA), hexanone, acetophenone (AP), and 2-OH acetophenone (THA); 5\%: IAA, hexanal, MS; 10\%: IAA, hexanal, MS]. All odorants are known dorsal $\mathrm{OB}$ ligands. Odorants were delivered using a custom built olfactometer controlled via TTL input from a HEKA ITC-18 external DA/AD/TTL device run by IGOR Pro (RRID:SCR_000325; Fig. 1B).

\section{Imaging}

Two-photon imaging was done in the MC layer $\sim 150$ $225 \mu \mathrm{m}$ under the pial surface using a VIVO 2-Photon system from 3I Intelligent Imaging Innovations and SlideBook Imaging software. Image capture rate was 6-9 Hz.

\section{Analysis}

The dataset consists of 863 putative mitral cells (MCs) from 17 mice $(225$ cells from one female and four male control mice, 269 cells from two female and four male mint-exposed mice, and 369 cells from two female and four male hexanal exposed) for a total of 12,082 cell-odor pairs. To select regions of interest (ROls), cell somata in each field of view were traced manually using SlideBook software and avoiding intersecting cell processes as determined by Z-stacks of each field of view (Fig. 1C). Presence or lack of odor-evoked response was not taken into account when identifying cells. Rather, all identified fluorescent cells were included. Raw intensity values were calculated using SlideBook software. $\Delta \mathrm{F} / \mathrm{F}$ traces were calculated using the average baseline intensity from the 20 frames before stimulus onset at $4 \mathrm{~s}$ after start of the trial. Traces were detrended by subtracting a polynomial fit from the calculated $\Delta \mathrm{F} / \mathrm{F}$ trace (Fig. $1 D$ ). We fit the 20 frames before odor onset ( $3 \mathrm{~s}$ before odor onset) and the last 45 frames ( $\sim 19 \mathrm{~s}$ after odor end) of each trace to a second degree polynomial and subtracted this fit from each trace. Response threshold was set at 3 SD away from baseline. Responses were only counted as successful if above this threshold, otherwise response was recorded as 0 . All analysis and visualization was done using Python (RRID:SCR_008394). Some statistical tests were performed using GraphPad Prism (RRID:SCR_002798).

\section{Results}

\section{Majority of MC odor-evoked responses were excitatory}

MC odor-evoked responses were dominated by excitatory responses, constituting 11,089 cell-odor pairs out of 12,082 total cell-odor pairs or $\sim 92 \%$ of all measured responses. Both peak $\Delta F / F$ (peak amplitude of $\Delta F / F$ response) and integral of odor-evoked response (integrated $\Delta \mathrm{F} / \mathrm{F})$ were calculated. A strong correlation between the peak and integral of individual responses was observed (Pearson's $r=0.97$; Fig. $2 C$ ), but there was no significant correlation between initial baseline intensity and either the peak (Pearson's $r=-0.0048$ ) or integral of responses (Pearson's $r=-0.018$; Fig. 2A,B). Thus, all data were pooled regardless of initial baseline intensity. Given the strong correlation between the peak and integral of odor-evoked response, subsequent data regarding odorant-evoked responses are shown as peak values. The distribution of all responses to all odorants are visualized in Figure 2D, with significant statistical differences observed between the response density functions of MCs from control, hexanal-exposed, and mint-exposed animals (Kruskal--Wallis test with Tukey's multiple comparisons test; $p=6.65 \mathrm{E}-199$; adjusted $p$ values between groups approximated 0 ).

We observe significant cell population differences in response between the control and each of the odorexposed groups. We next assessed potential differences in odor-evoked response based on subject sex. When examining only male mice (Fig. $2 E$ ), we find that the response distributions are different between hexanalexposed and control mice (Kruskal--Wallis, $p=1.13 \mathrm{E}-$ $66)$, but not different between mint-exposed and control mice (Kruskal--Wallis, $p=0.69$ ). However, when examining cell responses from female mice (Fig. $2 F$ ), we find that the distributions of cell responses from both groups of odor-exposed animals significantly differ from the distribution of control mouse responses (Kruskal--Wallis; control vs hexanal exposed: $p=1.29 \mathrm{E}-97$; control vs mint exposed: $p=1.02 \mathrm{E}-81)$. The sample size of female mice ( $n=1$ control, two mint-exposed and two hexanalexposed female mice) was not sufficient to draw specific conclusions about the role of sex in amplifying odorevoked responses following early odorant exposure. Given the small animal number, we cannot determine if these intergroup differences are due to interanimal variability or sexual dimorphism. Male and female mice pooled across groups did not have significantly different ages (Student's $t$ test; male vs female; $n=12$ vs 5; mean $\mathrm{P} 48.67 \pm 6.56$ vs P41.8 $\pm 9.24 ; p=0.57$ ).

\section{Amplitude of excitatory response increases following early odorant exposure}

Several additional features of the odor-evoked response change significantly following early odorant exposure, namely amplitude, number, and reliability of response. The amplitude of excitatory odor-evoked responses increased significantly for cells in both odorexposed groups as compared to cells in the control animals (Fig. 3A). Figure $3 B$ shows clear differences in 
A

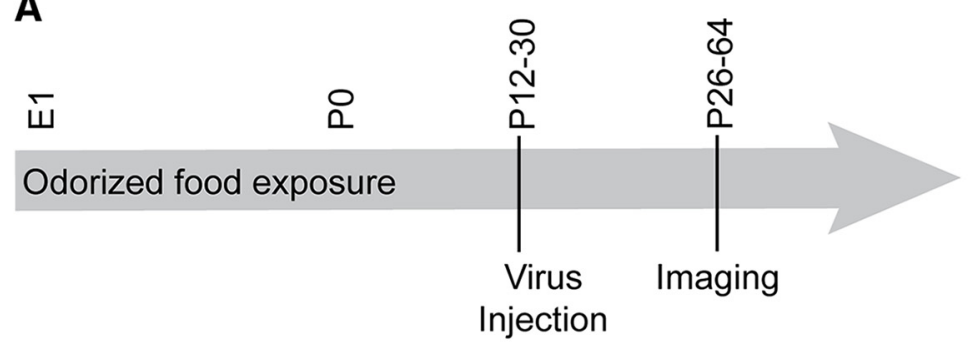

B

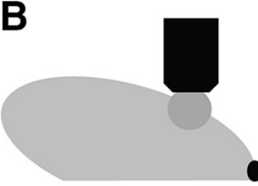

C

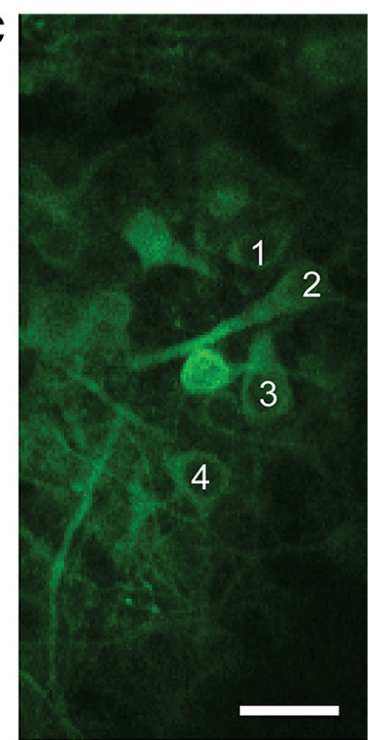

Aquarium Pump

D
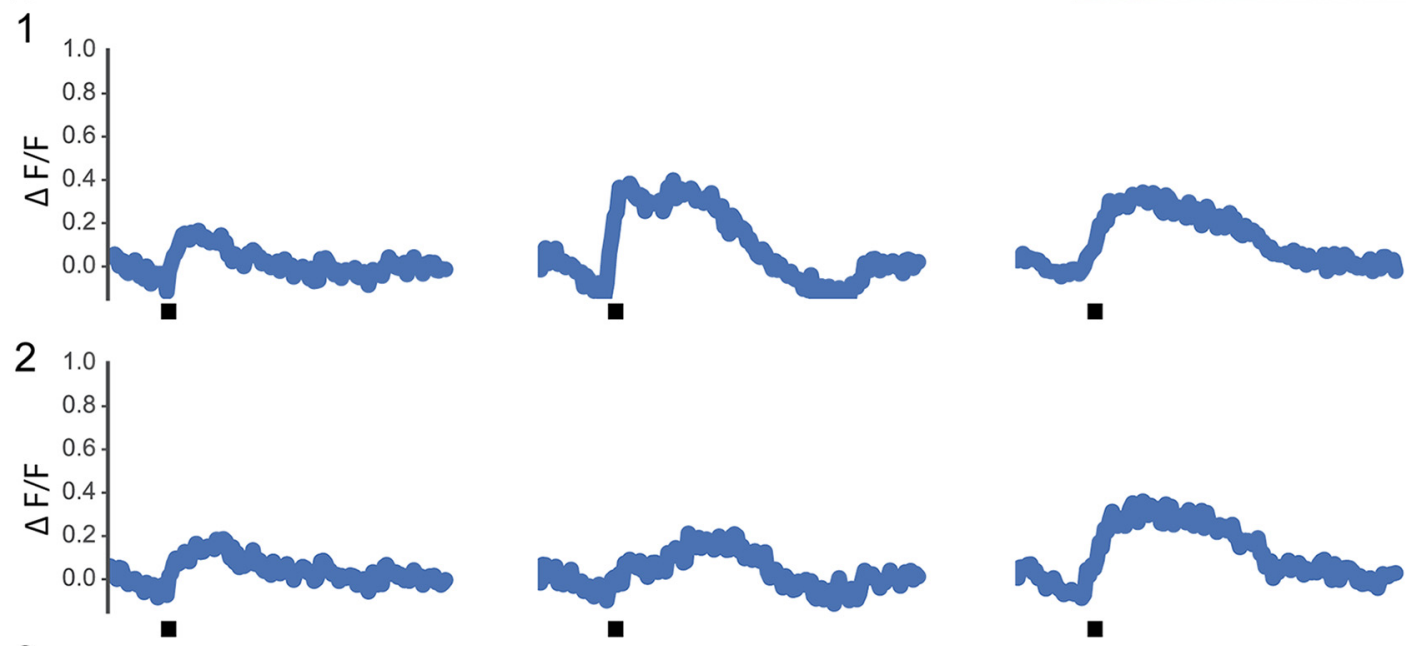

3
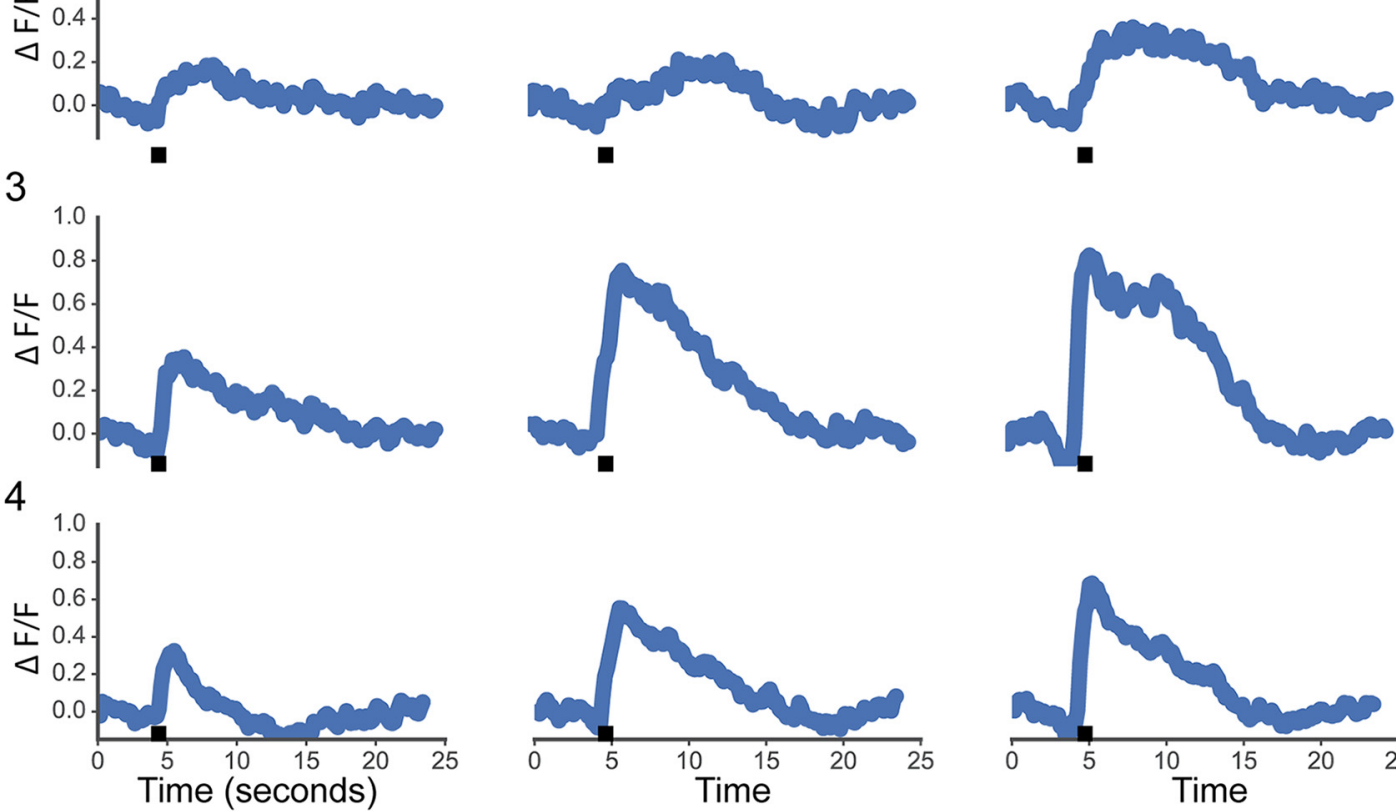

Methyl salicylate $1 \%$
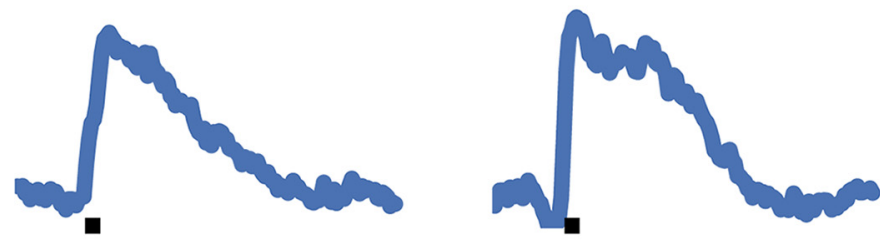

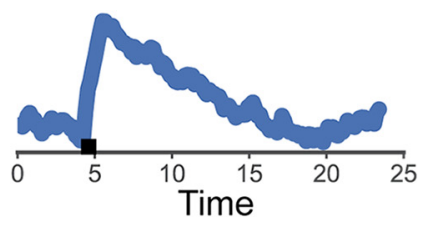

Methyl salicylate $5 \%$

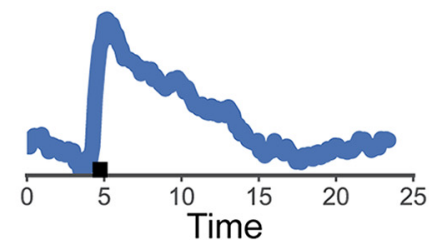

Methyl salicylate $10 \%$

Figure 1. Odor-evoked calcium responses in the MC layer. A, Odorized food exposure lasted through the entirety of gestation and the postnatal period until imaging. Virus injection into the dorsal OB was done at P12-P30. Imaging was performed two to three weeks after virus injection. $\boldsymbol{B}$, The dorsal $\mathrm{OB}$ was imaged during stimulus presentation using a custom-built 2-channel olfactometer with airflow provided by an aquarium pump. C, The MC layer was imaged with manual ROI selection. Four cells are labeled, with corresponding odor-evoked responses shown in $\boldsymbol{D}$. White scale bar: $25 \mu \mathrm{m}$. Black bar indicates 1-s odor stimulus. 
A
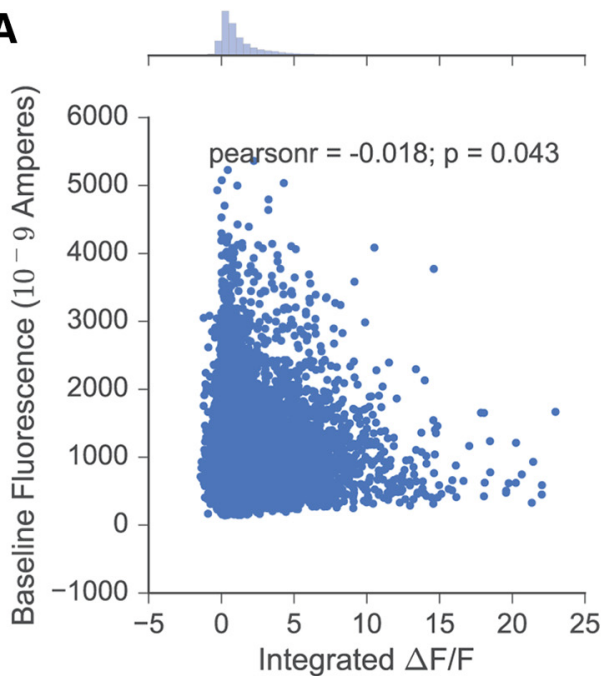

C

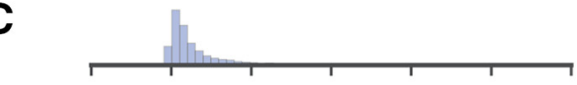

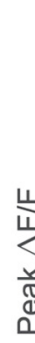

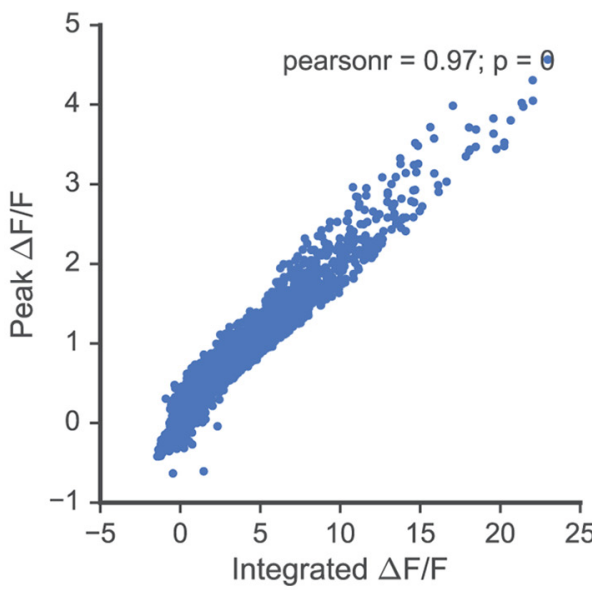

E

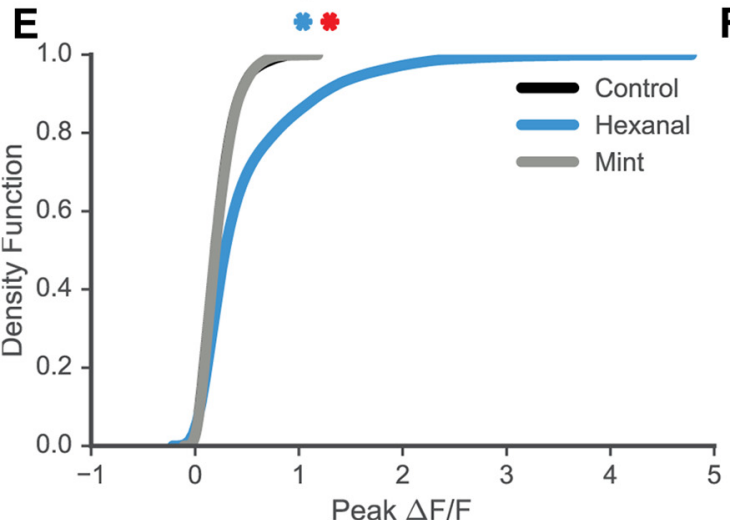

B

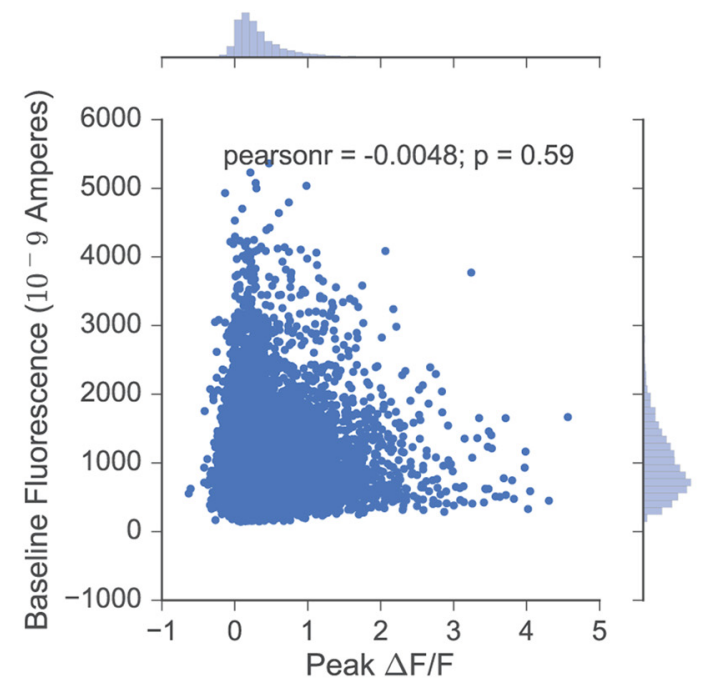

D

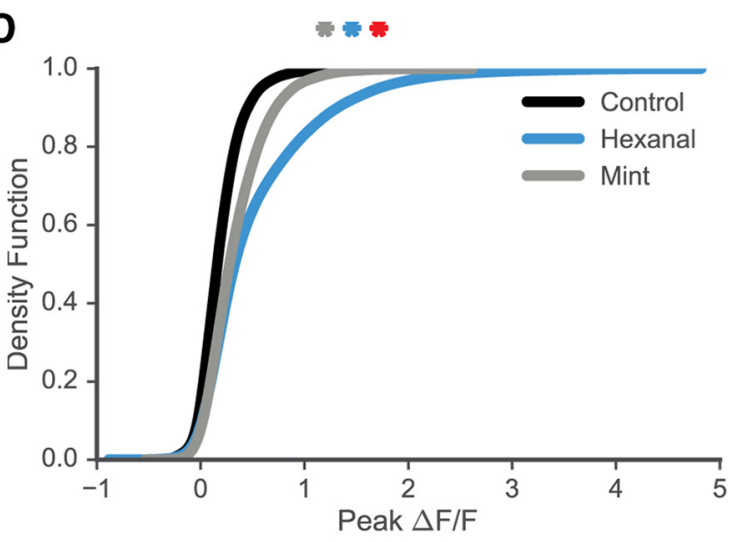

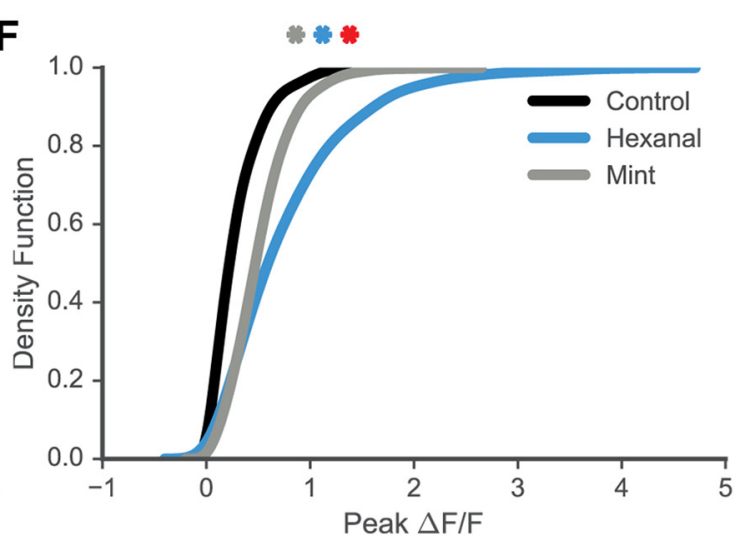

Figure 2. Response characteristics. $\boldsymbol{A}$, Integrated $\Delta \mathrm{F} / \mathrm{F}$ and baseline fluorescence are not correlated. $\boldsymbol{B}, \mathrm{Peak} \Delta \mathrm{F} / \mathrm{F}$ and baseline fluorescence are not correlated. $\boldsymbol{C}$, Peak and integrated $\Delta F / F$ are strongly correlated. $\boldsymbol{D}$, Kernel density estimation (KDE) describing response distribution across all cells and odorants in control, hexanal-exposed, and mint-exposed mice (statistically significant distributions between groups). $\boldsymbol{E}$, KDE describing response distribution across cells in control, hexanal-exposed, and mint-exposed male mice. $\boldsymbol{F}, \mathrm{KDE}$ describing response distribution across cells in control, hexanal-exposed, and mint-exposed female mice. Gray asterisk, statistically significant difference between mint and control groups; blue asterisk, statistically significant difference between hexanal and control; red asterisk, statistically significant difference between hexanal and mint. 
A

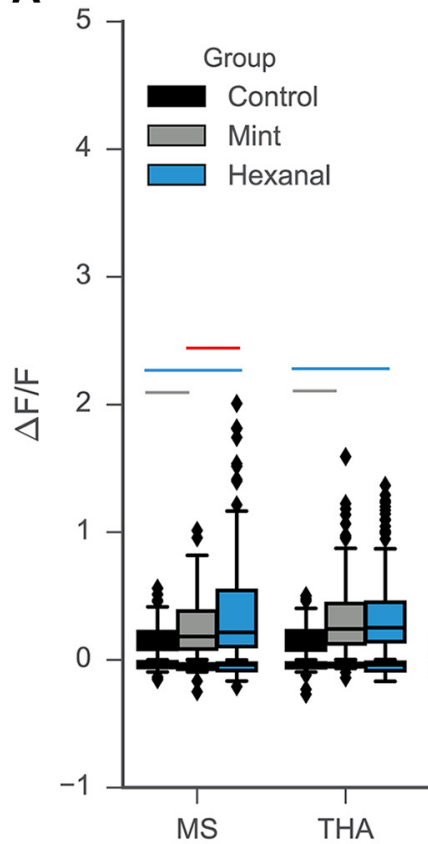

Peak $\Delta F / F, 1 \%$

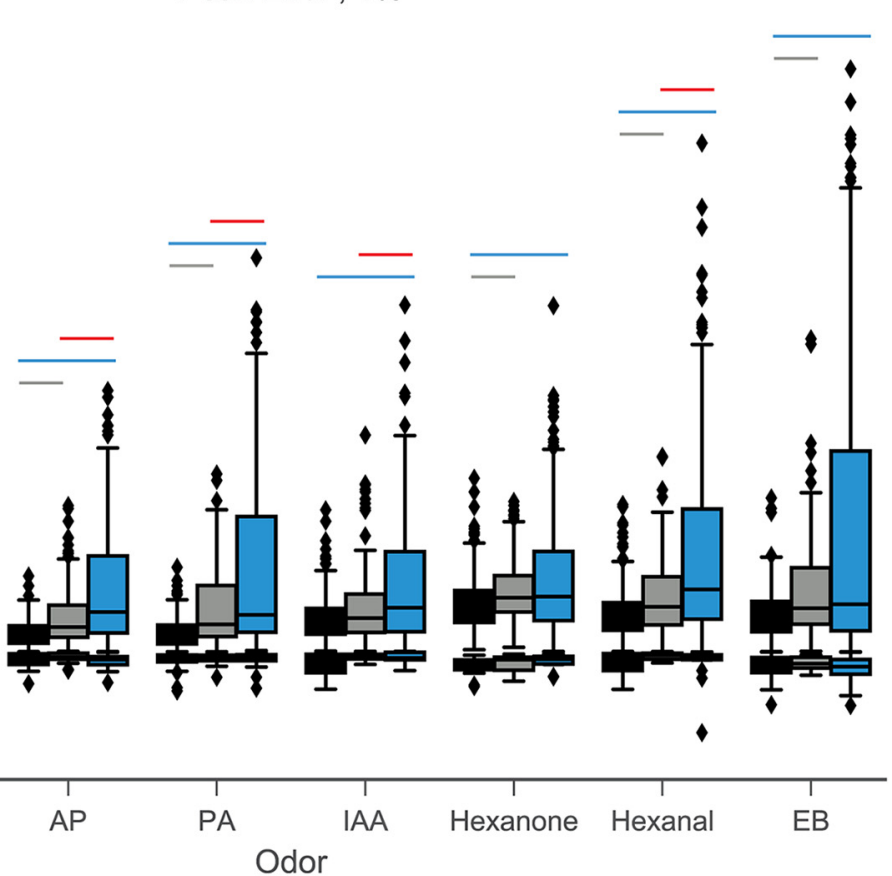

B

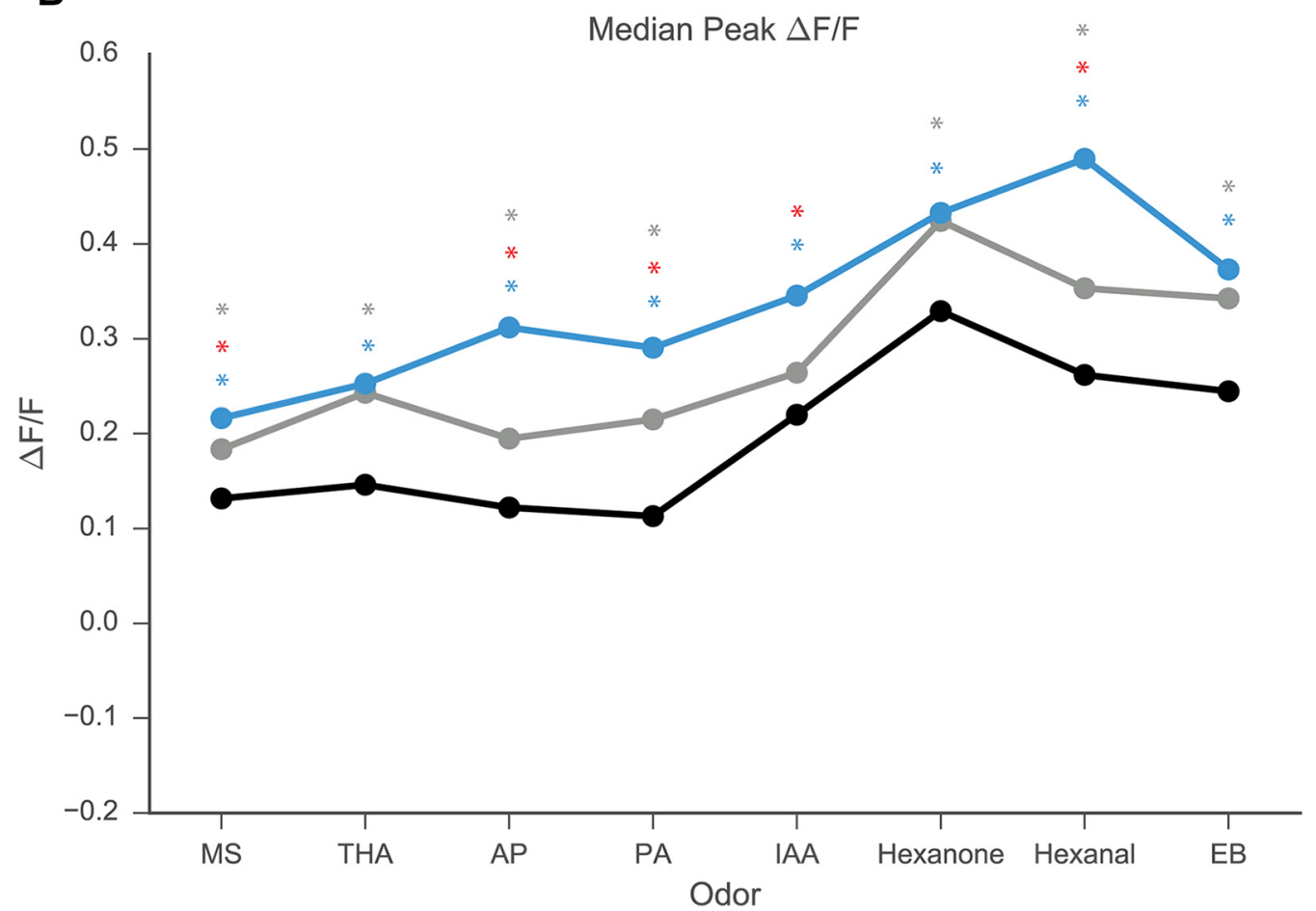

Figure 3. Odor exposure increases median Peak $\Delta \mathrm{F} / \mathrm{F}$ of $\mathrm{MC}$ response to odorants at $1 \%$ concentration by volume. $\boldsymbol{A}$, Boxplot describing distribution of peak odor-evoked $\Delta \mathrm{F} / \mathrm{F}$ of $\mathrm{MC}$ response to odorants at $1 \%$ concentration by volume. $\boldsymbol{B}, \mathrm{Median}$ peak $\Delta \mathrm{F} / \mathrm{F}$ across all odorants at $1 \%$ concentration by volume. Gray asterisk, statistically significant difference between mint and control groups; blue asterisk, statistically significant difference between hexanal and control; red asterisk, statistically significant difference between hexanal and mint.

median $\Delta \mathrm{F} / \mathrm{F}$ across all odorants at $1 \%$ concentration for control versus hexanal- and mint-exposed and for hexanal versus mint-exposed. This increase in response amplitude is not odor-specific, but rather is observed for almost all odors and concentrations in the odor stimulus panel (Figs. 3, 4). Descriptive and odorspecific group comparison statistics can be found in Table 1. 
A

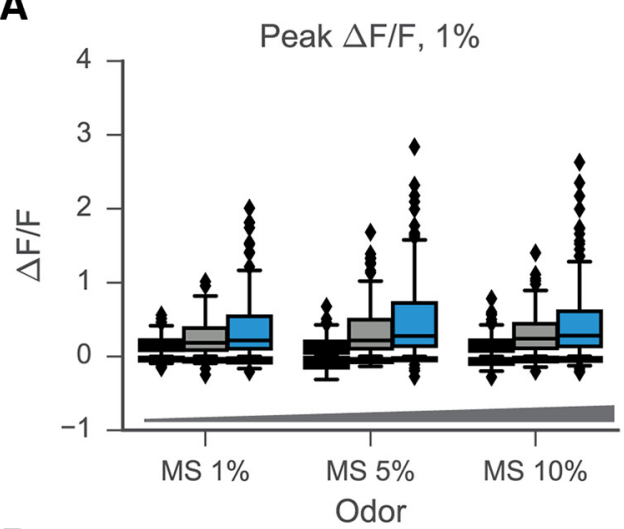

B

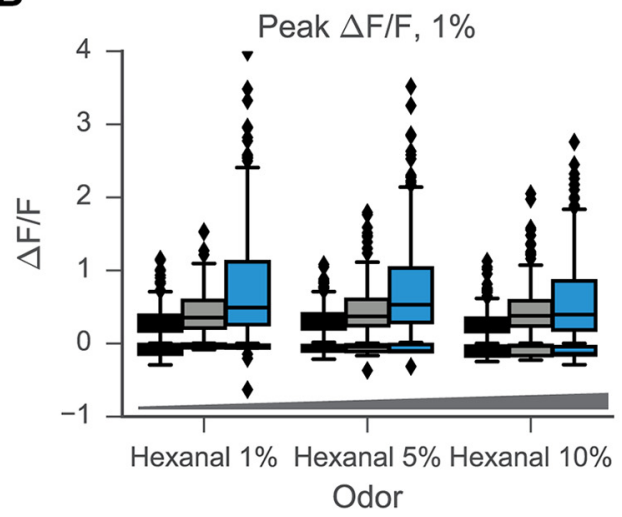

C

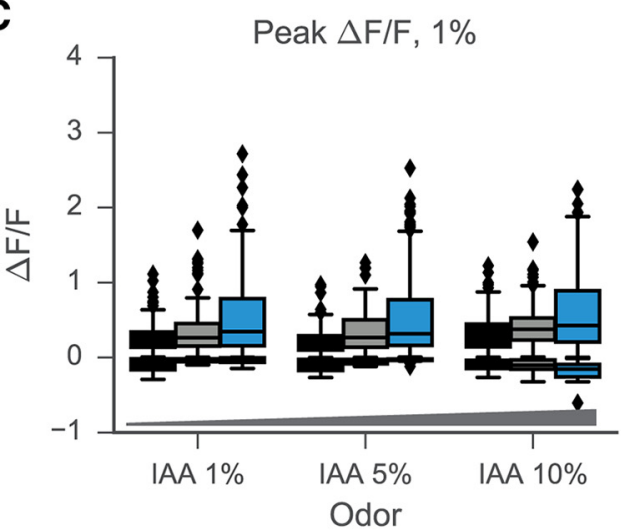

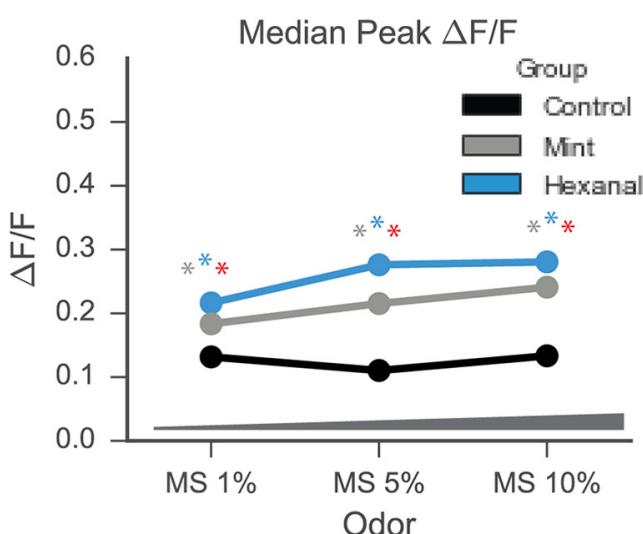
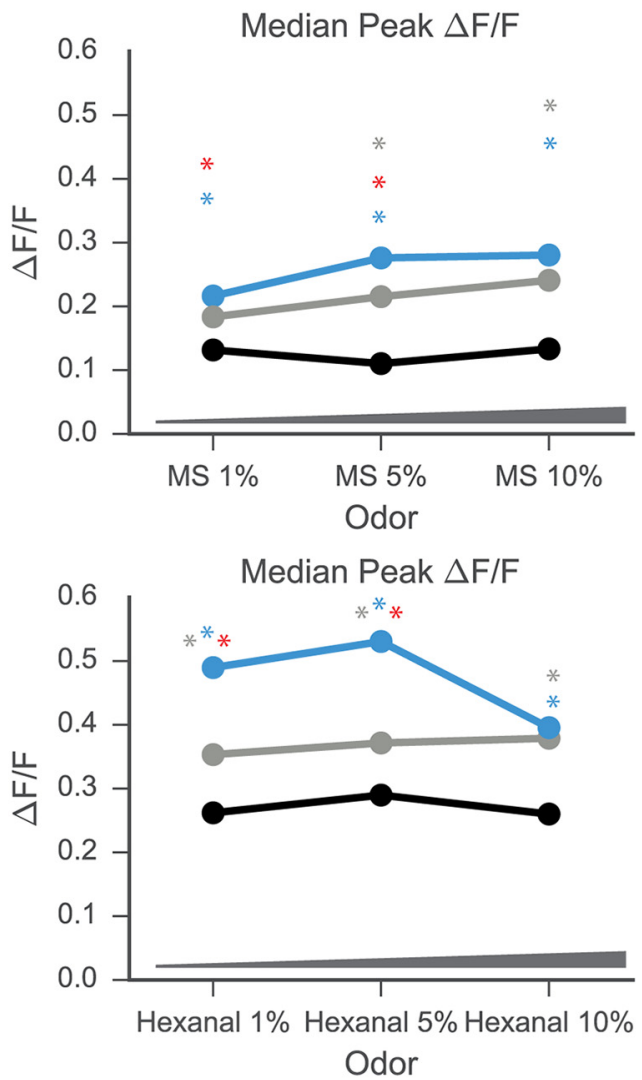

Figure 4. Odor exposure increases median Peak $\Delta \mathrm{F} / \mathrm{F}$ of $\mathrm{MC}$ response to odorants across concentrations. Mint-exposed and hexanal-exposed MCs have higher medians of peak $\Delta \mathrm{F} / \mathrm{F}$ across all concentrations of MS $(\boldsymbol{A})$, IAA $(\boldsymbol{B})$, and hexanal $(\boldsymbol{C})$. There were no significant differences in response distribution between concentrations for any exposure group.

Within-group differences in responses to the same odorant were also observed across concentrations (Fig. 4). However, these concentration differences were largely similar between the control, mint-exposed, and hexanalexposed groups, suggesting that the increased responsiveness seen following odor exposure was not specific to a single concentration. There were two combinations of odorants and concentrations for which significant differences were observed in all three exposure groups, two additional combinations with significant differences observed in only the control group, 1 additional observed in the mint-exposed group, and two additional observed in the hexanal-exposed group (Kruskal--Wallis test with
Tukey's multiple comparisons). Full details about statistical comparisons available in Table 2.

\section{Early odorant exposure increases the number and reliability of excitatory responses}

The proportion of excitatory responses increases following prenatal and early postnatal odorant exposure (Fig. $5 A-D$; Table 3; ANOVA with Tukey's multiple comparisons test; $p<0.0001$; medians: control, 0.88; mint, 0.9235; hexanal, 0.9377; significant Tukey's tests for control vs mint and control vs hexanal). The mint-exposed and hexanal-exposed groups both had a significantly larger proportion of excitatory responses than the control group. 
Table 1. Comparisons of excitatory response amplitude, $1 \%$ odorant concentration

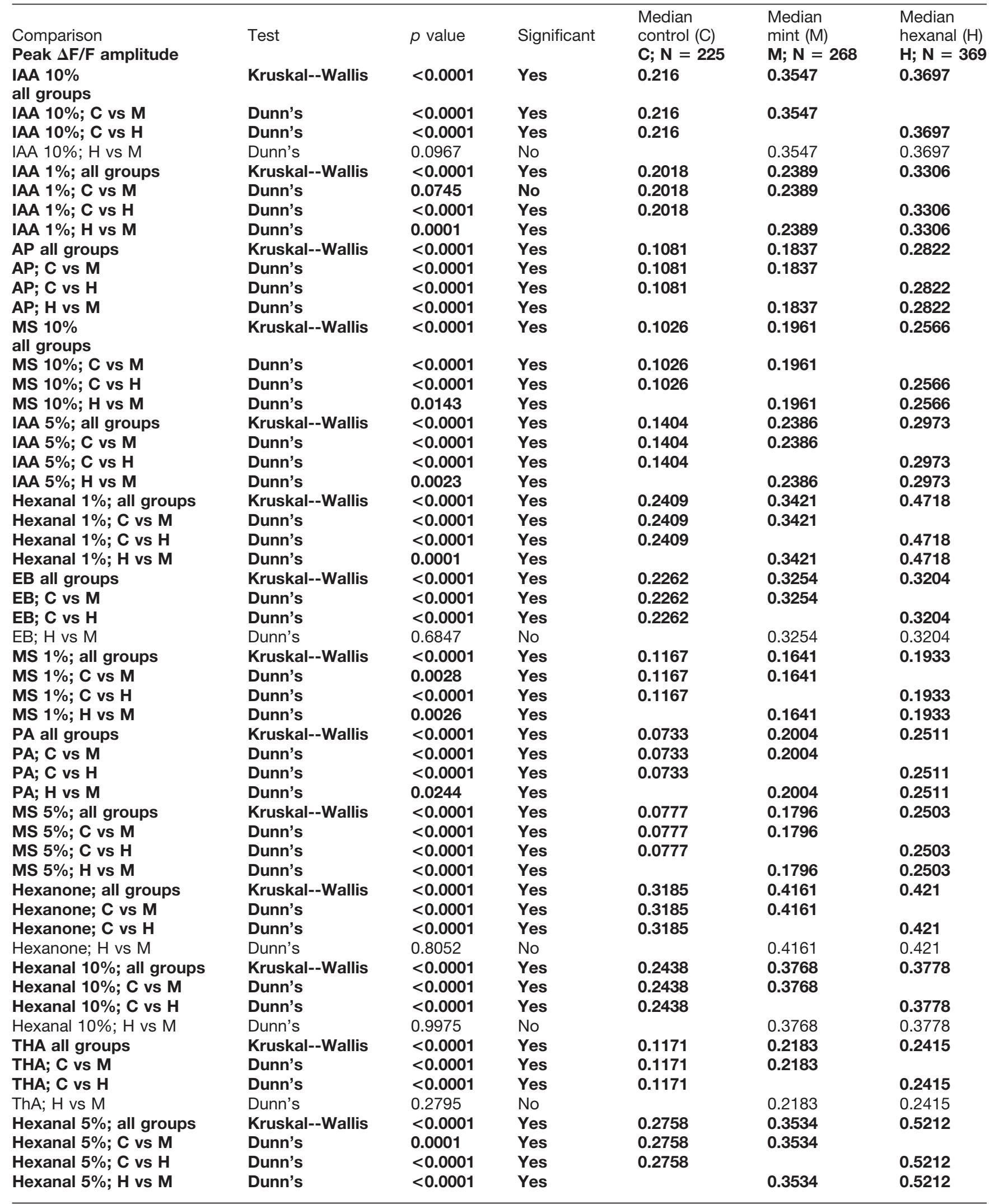

Statistical test results of excitatory response amplitudes of cells from control, mint-, and hexanal-exposed groups in response to odorants at $1 \%$ concentration. Data shown in Figure 3. 
Table 2. Comparisons of excitatory response amplitude, multiple concentrations

\begin{tabular}{|c|c|c|c|c|c|c|}
\hline $\begin{array}{l}\text { Comparison } \\
\text { Peak } \Delta F / F \text { amplitude } \\
\text { Control group }\end{array}$ & Test & $p$ value & Significant & $\begin{array}{l}\text { Median } \\
\text { control (C) } \\
\mathbf{C} ; \mathbf{N}=\mathbf{2 2 5}\end{array}$ & $\begin{array}{l}\text { Median } \\
\text { mint (M) } \\
\mathbf{M} ; \mathbf{N}=\mathbf{2 6 8}\end{array}$ & $\begin{array}{l}\text { Median } \\
\text { hexanal }(\mathrm{H}) \\
\mathbf{H} ; \mathbf{N}=\mathbf{3 6 9}\end{array}$ \\
\hline MS all conc. & Kruskal--Wallis & 0.0586 & No & 0.1167 & 0.0777 & 0.1026 \\
\hline MS; $1 \%$ vs $5 \%$ & Dunn's & 0.0508 & Yes & 0.1167 & 0.0777 & \\
\hline MS; $1 \%$ vs $10 \%$ & Dunn's & 0.4478 & No & 0.1167 & & 0.1026 \\
\hline MS; $5 \%$ vs $10 \%$ & Dunn's & 0.4695 & No & & 0.0777 & 0.1026 \\
\hline IAA all conc. & Kruskal--Wallis & $<0.0001$ & Yes & 0.2018 & 0.1404 & 0.216 \\
\hline IAA; $1 \%$ vs $5 \%$ & Dunn's & 0.0028 & Yes & 0.2018 & 0.1404 & \\
\hline IAA; $1 \%$ vs $10 \%$ & Dunn's & 0.768 & No & 0.2018 & & 0.216 \\
\hline IAA; $5 \%$ vs $10 \%$ & Dunn's & 0.0001 & Yes & & 0.1404 & 0.216 \\
\hline Hexanal; all conc. & Kruskal--Wallis & 0.0214 & Yes & 0.2409 & 0.2758 & 0.2438 \\
\hline Hexanal; $1 \%$ vs $5 \%$ & Dunn's & 0.1657 & No & 0.2409 & 0.2758 & \\
\hline Hexanal; $1 \%$ vs $10 \%$ & Dunn's & 0.8025 & No & 0.2409 & & 0.2438 \\
\hline $\begin{array}{l}\text { Hexanal; } 5 \% \text { vs } 10 \% \\
\text { Mint group }\end{array}$ & Dunn's & 0.0206 & Yes & & 0.2758 & 0.2438 \\
\hline MS; all conc. & Kruskal--Wallis & 0.206 & No & 0.1642 & 0.1796 & 0.1961 \\
\hline MS; $1 \%$ vs $5 \%$ & Dunn's & 0.0194 & Yes & 0.1642 & 0.1796 & \\
\hline MS; $1 \%$ vs $10 \%$ & Dunn's & 0.1692 & No & 0.1642 & & 0.1961 \\
\hline MS; $5 \%$ vs $10 \%$ & Dunn's & 0.7856 & No & & 0.1796 & 0.1961 \\
\hline IAA; all conc. & Kruskal--Wallis & $<0.000 \mathrm{~A} 1$ & Yes & 0.2389 & 0.2386 & 0.3547 \\
\hline IAA; $1 \%$ vs $5 \%$ & Dunn's & 0.9991 & No & 0.2389 & 0.2386 & \\
\hline IAA; $1 \%$ vs $10 \%$ & Dunn's & 0.0001 & Yes & 0.2389 & & 0.3547 \\
\hline IAA; $5 \%$ vs $10 \%$ & Dunn's & 0.0001 & Yes & & 0.2386 & 0.3547 \\
\hline Hexanal; all conc. & Kruskal--Wallis & 0.3426 & No & 0.3421 & 0.3534 & 0.3768 \\
\hline Hexanal; $1 \%$ vs $5 \%$ & Dunn's & 0.7615 & No & 0.3421 & 0.3534 & \\
\hline Hexanal; $1 \%$ vs $10 \%$ & Dunn's & 0.3775 & No & 0.3421 & & 0.3768 \\
\hline $\begin{array}{l}\text { Hexanal; } 5 \% \text { vs } 10 \% \\
\text { Hexanal group }\end{array}$ & Dunn's & 0.9178 & No & & 0.3534 & 0.3768 \\
\hline MS; all conc. & Kruskal--Wallis & 0.0184 & Yes & 0.1933 & 0.2503 & 0.2566 \\
\hline MS; $1 \%$ vs $5 \%$ & Dunn's & 0.0146 & Yes & 0.1933 & 0.2503 & \\
\hline MS; $1 \%$ vs $10 \%$ & Dunn's & 0.2718 & No & 0.1933 & & 0.2566 \\
\hline MS; $5 \%$ vs $10 \%$ & Dunn's & 0.5645 & No & & 0.2503 & 0.2566 \\
\hline IAA; all conc. & Kruskal--Wallis & 0.0433 & Yes & 0.3306 & 0.2973 & 0.3697 \\
\hline IAA; $1 \%$ vs $5 \%$ & Dunn's & 0.8326 & No & 0.3306 & 0.2973 & \\
\hline IAA; $1 \%$ vs $10 \%$ & Dunn's & 0.2488 & No & 0.3306 & & 0.3697 \\
\hline IAA; $5 \%$ vs $10 \%$ & Dunn's & 0.0425 & Yes & & 0.2973 & 0.3697 \\
\hline Hexanal; all conc. & Kruskal--Wallis & $<0.0001$ & Yes & 0.4718 & 0.5212 & 0.3778 \\
\hline Hexanal; $1 \%$ vs $5 \%$ & Dunn's & 0.3105 & No & 0.4718 & 0.5212 & \\
\hline Hexanal; $1 \%$ vs $10 \%$ & Dunn's & 0.0137 & Yes & 0.4718 & & 0.3778 \\
\hline Hexanal; $5 \%$ vs $10 \%$ & Dunn's & $<0.0001$ & Yes & & 0.5212 & 0.3778 \\
\hline
\end{tabular}

Statistical test results of excitatory response amplitudes of cells from control, mint-, and hexanal-exposed groups in response to odorants at $1 \%, 5 \%$, and $10 \%$ concentration. Data shown in Figure 4.

In addition, MCs of odor-exposed animals exhibited excitatory responses to more odorants than MCs of control animals (Fig. 5E; ANOVA with Tukey's multiple comparisons test; $p<0.0001$; medians: control, 13; mint, 14; hexanal, 14; significant Tukey's tests for control vs mint and control vs hexanal). These measures indicate that odor exposure increases excitatory MC odor-evoked responses, both in number and in number of activating odors.

Excitatory responses to certain odorants were also more reliable following odor-exposure, as measured by the proportion of successful trial presentations of each odorant (Fig. 6A-D; Table 4; data pooled across odorants; Kruskal--Wallis test with Dunn's multiple comparisons test; $p<0.0001$; medians: 1 for each group). As detailed in the Methods section, an excitatory response is defined as a peak $\Delta F / F$ at least 3 SD above average fluorescence intensity before stimulus onset. This increase in the reliability of MCs between control and odor-exposed groups ( 0.75 median control to 1 for each odor-exposed group) is significant for the following odorants: MS 1\% (Kruskal-Wallis test; $p=0.0139)$, MS 5\% ( $p<0.0001)$, MS 10\% ( $p$ $<0.0001)$, THA $(p<0.0001)$, AP $(p<0.0001)$, and PA ( $p$ $<0.0001$; Fig. $6 A$; additional descriptive statistics available in Table 4). The odorants for which reliability increased following odorant exposure are the ones within the panel that elicited relatively weaker responses, as measured by comparisons of their median evoked peak $\Delta F / F$ (Figs. 3, 4). Median success values were not different between groups for other odorants, although comparisons of distributions differed - these values are described in Table 4. These data together show that early odorant exposure increases the proportion and reliability of excitatory responses in a manner not dependent on the iden- 
A

Excitatory Responses
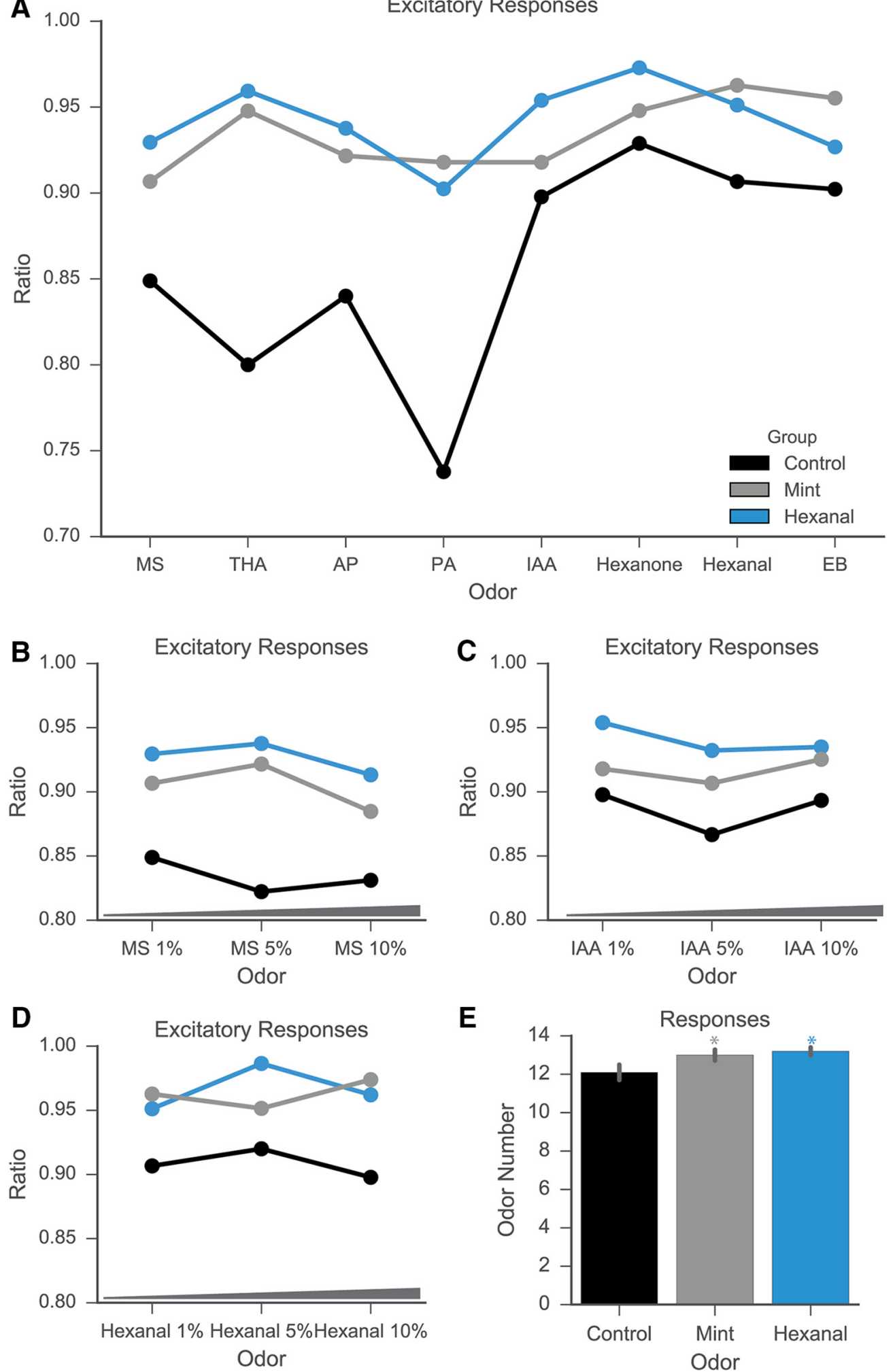

Figure 5. Odor exposure increases number of excitatory MC responses. $\boldsymbol{A}$-- $\boldsymbol{D}$, Ratio of above-threshold excitatory responses to all odor presentation trials across odorants. Odor-exposure groups had significantly higher ratio of excitatory responses as compared to control groups for odors at $1 \%$ concentration $(\boldsymbol{A})$ and multiple concentrations $(\boldsymbol{B}-\mathbf{-} \boldsymbol{D})$. $\boldsymbol{E}$, MCs in all groups responded to a high number of odorants (median number of odorants: control, 13; mint exposed, 14; hexanal exposed, 14). Gray asterisk, statistically significant difference between mint and control groups; blue asterisk, statistically significant difference between hexanal and control groups. 
Table 3. Proportion of excitatory responses

\begin{tabular}{|c|c|c|c|c|c|c|}
\hline Comparison & Test & $p$ value & Significant & $\begin{array}{l}\text { Median } \\
\text { control (C) }\end{array}$ & $\begin{array}{l}\text { Median } \\
\text { mint (M) }\end{array}$ & $\begin{array}{l}\text { Median } \\
\text { hexanal }(\mathrm{H})\end{array}$ \\
\hline Ratio of excitatory responses & & & & $C ; N=14$ & $M ; N=14$ & $H ; N=14$ \\
\hline All odors & ANOVA & $p<0.0001$ & Yes & 0.88 & 0.9235 & 0.9377 \\
\hline All odors; C vs $M$ & Tukey's & $p<0.0001$ & Yes & 0.88 & 0.9235 & \\
\hline All odors; C vs H & Tukey's & $p<0.0001$ & Yes & 0.88 & & 0.9377 \\
\hline All odors; $\mathrm{H}$ vs $\mathrm{M}$ & Tukey's & $p=0.1313$ & No & & 0.9235 & 0.9377 \\
\hline $\begin{array}{l}\text { Ratio of activating } \\
\text { odorants }\end{array}$ & & & & $C ; N=225$ & $M ; N=268$ & $H ; N=369$ \\
\hline All groups & Kruskal--Wallis & $p<0.0001$ & Yes & 13 & 14 & 14 \\
\hline C vs $M$ & Tukey's & $p<0.0001$ & Yes & 13 & 14 & \\
\hline C vs $\mathrm{H}$ & Tukey's & $p<0.0001$ & Yes & 13 & & 14 \\
\hline $\mathrm{H}$ vs $\mathrm{M}$ & Tukey's & $p>0.9999$ & No & & 14 & 14 \\
\hline
\end{tabular}

Comparisons of proportion of excitatory odor-evoked responses from control, mint-, and hexanal-exposed groups. Data shown in Figure 5.

tity of odorant used for exposure, much like the observed odor-nonspecific increases in excitatory response amplitude. Rather, the reliability of response increases in an odor-specific manner relative to the initial amplitude of odor-evoked response.

\section{Odorant exposure changes odor tuning}

Given the changes in excitatory response amplitude, number, and reliability, we next investigated whether chronic early odorant exposure also changes the odor tuning curve of cells from each exposure group. Because of the high dimensionality of odorant stimuli, we used a metric of odorant response ranking to construct a tuning curve based on the stimuli in our odor panel that can then be used to compare relative responses across exposure groups. For each cell, we assigned ranks to each odorant based on the average odor-evoked response amplitude. The odorant that evoked the highest response from the cell was assigned a rank of 14 , while the odorant that evoked the lowest response from the cell was assigned a rank of 1. A nonresponse to an odorant was scored as 0 amplitude and ranked accordingly, depending on if there were inhibitory and excitatory responses within the same cell. If the cell only exhibited excitatory responses, then the nonresponse to an odorant was given the rank of 1 . If two or more odorants elicited the same amplitude of odor-evoked response, such as a nonresponse, those odorants were given the same ranking. There were significant differences in the rank of specific odorants between control, mint-exposed, and hexanal-exposed groups (Fig. 7). Rather than graphically denote odorants that were different, we have listed these in table form in Figure $7 E$. For clarity, results of statistical comparisons and descriptive statistics are listed in Table 5. The control group $(n=$ 225 cells) differed from the mint-exposed group $(n=269$ cells) on six out of 14 possible odorant/concentration combinations (Kruskal--Wallis test followed by Dunn's multiple comparisons test). The control group differed from the hexanal-exposed group ( $n=369$ cells) on 10 out of 14 odorant/concentration combinations. Mint-exposed and hexanal-exposed groups differed on eight of 14 odorant/concentration combinations. These data show that food-based prenatal and postnatal odorant exposure does change MC tuning curves, as demonstrated by comparisons of individual odor ranks. There are also odor-specific differences between the mint-exposed and hexanal-exposed groups, suggesting that conditioning odorant identity could impact resultant changes in odorant response ranking.

\section{MCs exhibit habituation following repeated acute odor trials}

Previous work has demonstrated that repeated presentation of odors results in a decrease in amplitude of odor-evoked responses (Chaudhury et al., 2010; Ogg et al., 2015). Given that our odor exposure paradigm did not demonstrate this effect, we examined short term habituation in a subset of animals. In three animals, one from each group, we observed acute habituation of $\mathrm{MC}$ response. Each of these imaging sessions took place following acquisition of $\mathrm{MC}$ odor-evoked responses using the complete panel of odor stimuli. Using a protocol described by Chaudhury et al. (2010), we imaged hexanalevoked activity before stimulus, presented repeated blocks of short presentations of hexanal, and imaged hexanal-evoked activity 5 and $30 \mathrm{~min}$ after repeated hexanal presentation (Fig. $8 A$ ). We found prolonged decreases in odor-evoked responses $5 \mathrm{~min}$ and $30 \mathrm{~min}$ after the stimulus presentation ( $n=56$ cells) Friedman test with Tukey's multiple comparisons test; Median decrease in amplitude as percentage of initial "Pre" response: $37 \%$ for 5 min after stimulus and $35 \%$ for 30 min after stimulus; Pre versus 5 min: adjusted $p<0.0001$; Pre versus 30 min: adjusted $p<0.0001 ; 5$ vs 30 min: adjusted $p>0.9999$ (Fig. 8B). These cells demonstrate acute habituation following repeated stimulation similar to that observed in previous studies.

\section{Discussion}

Our data show that prenatal and early postnatal foodbased odor exposure increases the amplitude, number, and reliability of excitatory $\mathrm{MC}$ responses in vivo, as measured by 2-photon calcium imaging. We observed subtle changes to MC tuning curves between exposure groups, but we did not observe any changes in $\mathrm{MC}$ response that were specific to the conditioned odor. The mechanisms of these widespread changes are unclear and contrast with previous work using long-term postna- 

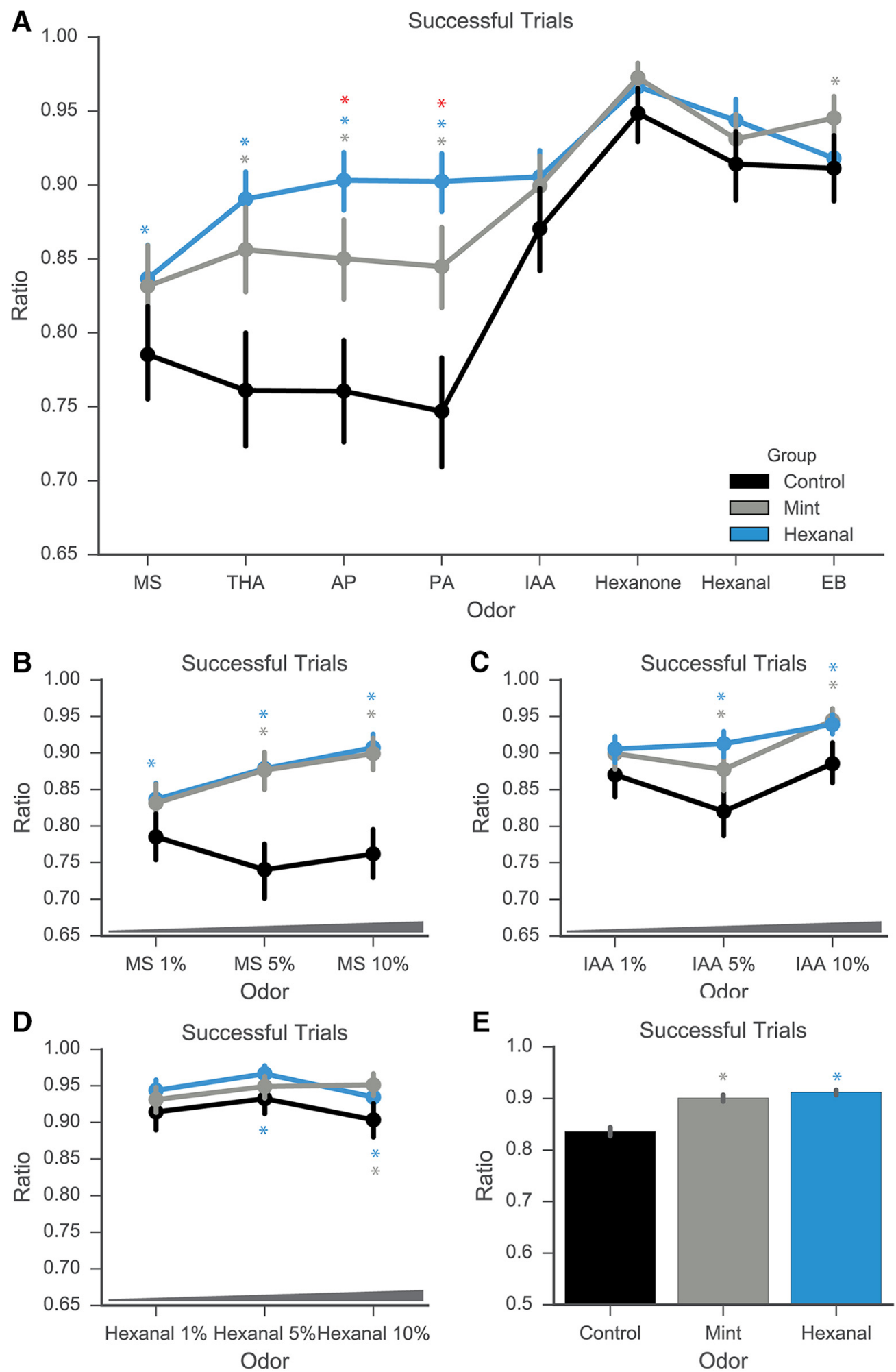

Figure 6. Odor exposure increases the rate of successful responses to odorant presentation. $\boldsymbol{A}-\mathbf{-} \boldsymbol{D}$, Ratio of successful trials above threshold (3 SD above baseline) to total trials of odorant presentation increases in odor-exposed groups across specific odorants at $1 \%$ concentration $(\boldsymbol{A})$ and multiple concentrations of MS $(\boldsymbol{B})$ and IAA $(\boldsymbol{C})$, but not hexanal $(\boldsymbol{D})$. $\boldsymbol{E}$, Summed across all trials, odor-exposed groups had higher overall ratio of successful trials. Gray asterisk, statistically significant difference between mint and control groups; blue asterisk, statistically significant difference between hexanal and control; red asterisk, statistically significant difference between hexanal and mint. 
Table 4. Reliability of excitatory responses

\begin{tabular}{|c|c|c|c|c|c|}
\hline $\begin{array}{l}\text { Comparison } \\
\text { Ratio of successful trials }\end{array}$ & Test & $p$ value & $\begin{array}{l}\text { Median } \\
\text { control (C) } \\
\mathbf{C} ; \mathbf{N}=\mathbf{2 2 5}\end{array}$ & $\begin{array}{l}\text { Median } \\
\text { mint (M) } \\
\mathbf{M} ; \mathbf{N}=\mathbf{2 6 8}\end{array}$ & $\begin{array}{l}\text { Median } \\
\text { hexanal }(\mathbf{H}) \\
\mathbf{H} ; \mathbf{N}=\mathbf{3 6 9}\end{array}$ \\
\hline All odors combined; all groups & Kruskal--Wallis & $<0.0001$ & 1 & 1 & 1 \\
\hline All odors combined; C vs $\mathbf{M}$ & Dunn's & $<0.0001$ & 1 & 1 & \\
\hline All odors combined; C vs $\mathrm{H}$ & Dunn's & $<0.0001$ & 1 & & 1 \\
\hline All odors combined; $\mathrm{H}$ vs $\mathrm{M}$ & Dunn's & 0.0836 & & 1 & 1 \\
\hline AP all groups & Kruskal--Wallis & $<0.0001$ & 0.75 & 1 & 1 \\
\hline AP; C vs $M$ & Dunn's & $<0.0001$ & 0.75 & 1 & \\
\hline AP; C vs H & Dunn's & $<0.0001$ & 0.75 & & 1 \\
\hline AP; H vs M & Dunn's & 0.0029 & & 1 & 1 \\
\hline EB all groups & Kruskal--Wallis & 0.0181 & 1 & 1 & 1 \\
\hline EB; C vs M & Dunn's & 0.0151 & 1 & 1 & \\
\hline $\mathrm{EB} ; \mathrm{C}$ vs $\mathrm{H}$ & Dunn's & 0.5476 & 1 & & 1 \\
\hline EB; H vs M & Dunn's & 0.2351 & & 1 & 1 \\
\hline Hexanal 1\%; all groups & Kruskal--Wallis & 0.0596 & 1 & 1 & 1 \\
\hline Hexanal $1 \%$; C vs M & Dunn's & 0.7821 & 1 & 1 & \\
\hline Hexanal $1 \%$; C vs H & Dunn's & 0.0562 & 1 & & 1 \\
\hline Hexanal 1\%; H vs M & Dunn's & 0.6464 & & 1 & 1 \\
\hline Hexanone; all groups & Kruskal--Wallis & 0.1165 & 1 & 1 & 1 \\
\hline Hexanone; C vs M & Dunn's & 0.1277 & 1 & 1 & \\
\hline Hexanone; C vs H & Dunn's & 0.3668 & 1 & & 1 \\
\hline Hexanone; $\mathrm{H}$ vs $\mathrm{M}$ & Dunn's & $>0.9999$ & & 1 & 1 \\
\hline IAA $1 \%$ all groups & Kruskal--Wallis & 0.0902 & 1 & 1 & 1 \\
\hline IAA $1 \%$; C vs M & Dunn's & 0.4431 & 1 & & 1 \\
\hline IAA 1\%; C vs H & Dunn's & 0.0867 & 1 & 1 & \\
\hline IAA 1\%; H vs M & Dunn's & $>0.9999$ & & 1 & 1 \\
\hline $\begin{array}{l}\text { MS } 1 \% \\
\text { all groups }\end{array}$ & Kruskal--Wallis & 0.0139 & 0.75 & 1 & 1 \\
\hline MS $1 \% ; C$ vs $M$ & Dunn's & 0.0621 & 0.75 & 1 & \\
\hline MS $1 \%$; C vs H & Dunn's & 0.0144 & 0.75 & & 1 \\
\hline MS 1\%; H vs M & Dunn's & $>0.9999$ & & 1 & 1 \\
\hline PA all groups & Kruskal--Wallis & $<0.0001$ & 0.75 & 1 & 1 \\
\hline PA; C vs M & Dunn's & $<0.0001$ & 0.75 & 1 & \\
\hline PA; C vs H & Dunn's & $<0.0001$ & 0.75 & & 1 \\
\hline PA; H vs M & Dunn's & 0.0019 & & 1 & 1 \\
\hline THA all groups & Kruskal--Wallis & $<0.0001$ & 0.75 & 1 & 1 \\
\hline THA; C vs M & Dunn's & $<0.0001$ & 0.75 & 1 & \\
\hline THA; C vs H & Dunn's & $<0.0001$ & 0.75 & & 1 \\
\hline THA; H vs M & Dunn's & 0.9588 & & 1 & 1 \\
\hline MS 5\%; all groups & Kruskal--Wallis & $<0.0001$ & 0.75 & 1 & 1 \\
\hline MS $5 \%$; C vs M & Dunn's & $<0.0001$ & 0.75 & 1 & \\
\hline MS 5\%; C vs H & Dunn's & $<0.0001$ & 0.75 & & 1 \\
\hline MS 5\%; H vs M & Dunn's & $>0.9999$ & & 1 & 1 \\
\hline MS $10 \%$; all groups & Kruskal--Wallis & $<0.0001$ & 0.75 & 1 & 1 \\
\hline MS $10 \%$; C vs M & Dunn's & $<0.0001$ & 0.75 & 1 & \\
\hline MS $10 \%$; C vs H & Dunn's & $<0.0001$ & 0.75 & & 1 \\
\hline MS 10\%; H vs M & Dunn's & $>0.9999$ & & 1 & 1 \\
\hline Hexanal 5\%; all groups & Kruskal--Wallis & 0.0016 & 1 & 1 & 1 \\
\hline Hexanal $5 \%$; C vs M & Dunn's & 0.4815 & 1 & 1 & \\
\hline Hexanal $5 \%$; C vs H & Dunn's & 0.0014 & 1 & & 1 \\
\hline Hexanal 5\%; H vs M & Dunn's & 0.1031 & & 1 & 1 \\
\hline Hexanal $10 \%$; all groups & Kruskal--Wallis & 0.0001 & 1 & 1 & 1 \\
\hline Hexanal $10 \%$; C vs M & Dunn's & 0.0001 & 1 & 1 & \\
\hline Hexanal $10 \%$; C vs H & Dunn's & 0.0029 & 1 & & 1 \\
\hline Hexanal $10 \%$; H vs M & Dunn's & 0.81 & & 1 & 1 \\
\hline IAA 5\%; all groups & Kruskal--Wallis & $<0.0001$ & 1 & 1 & 1 \\
\hline IAA 5\%; C vs M & Dunn's & 0.0026 & 1 & 1 & \\
\hline IAA $5 \%$; C vs H & Dunn's & $<0.0001$ & 1 & & 1 \\
\hline IAA 5\%; H vs M & Dunn's & 0.4956 & & 1 & 1 \\
\hline IAA 10\%; all groups & Kruskal--Wallis & 0.0007 & 1 & 1 & 1 \\
\hline IAA $10 \%$; C vs M & Dunn's & 0.0007 & 1 & 1 & \\
\hline IAA $10 \%$; C vs H & Dunn's & 0.01 & 1 & & 1 \\
\hline IAA $10 \% ; H$ vs $M$ & Dunn's & 0.8374 & & 1 & 1 \\
\hline
\end{tabular}

Comparisons of excitatory response reliability from control, mint-, and hexanal-exposed groups. Data shown in Figure 6. 
A

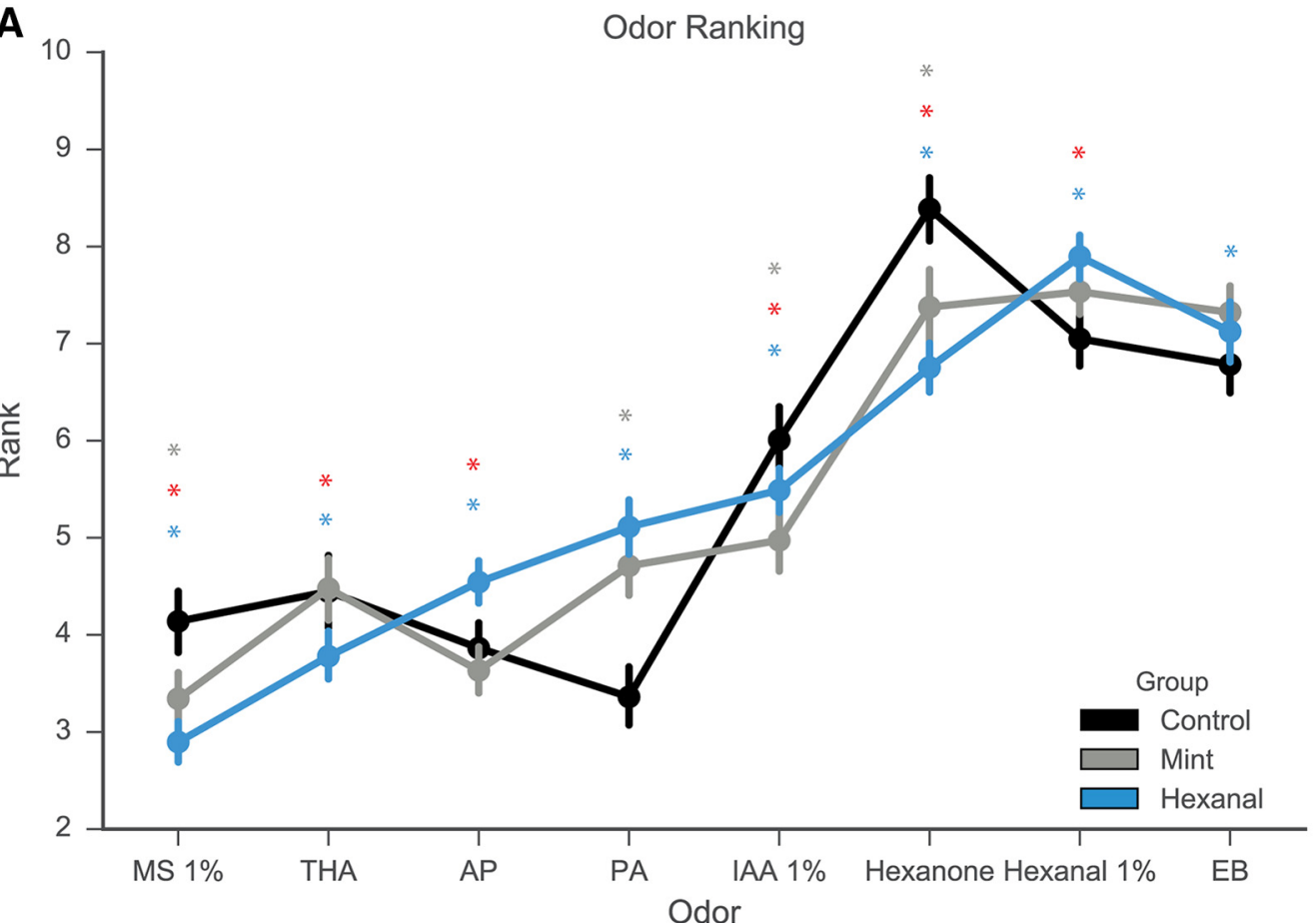

B

C

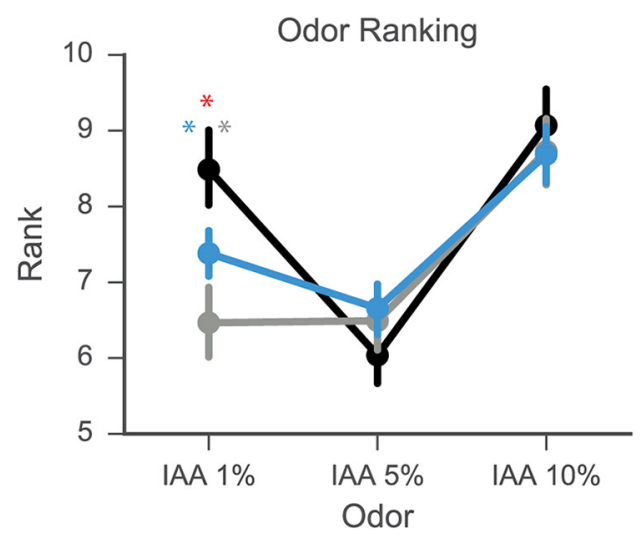

\section{D}

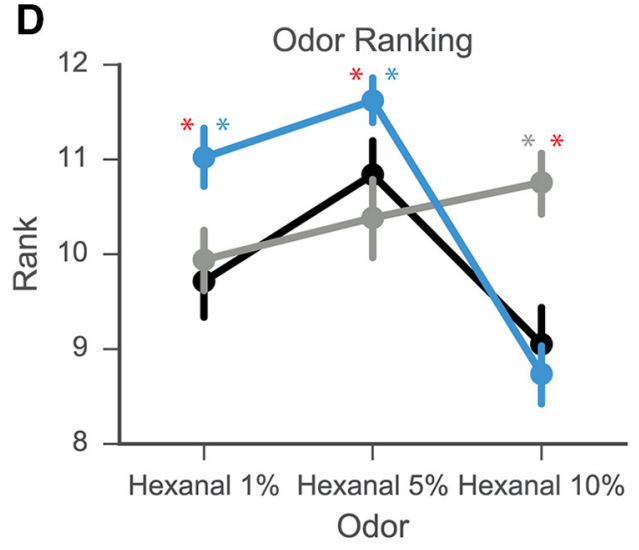

E

\begin{tabular}{|c|c|c|}
\hline \multicolumn{3}{|c|}{ Significant Comparisons } \\
\hline C vs. M & $\begin{array}{l}\text { C vs. } \mathbf{H} \\
\mathrm{AP}\end{array}$ & $\begin{array}{l}\mathbf{H} \text { vs. } \mathbf{M} \\
\text { AP }\end{array}$ \\
\hline hexanone & $\begin{array}{l}\text { EB } \\
\text { hexanone }\end{array}$ & hexanone \\
\hline & $\begin{array}{l}\text { PA } \\
\text { THA }\end{array}$ & \\
\hline hexanal, $10 \%$ & hexanal, $1 \%$ & hexanal, $1 \%$ \\
\hline IAA, 1\% & $\begin{array}{l}\text { hexanal, } 5 \% \\
\text { IAA, } 1 \%\end{array}$ & $\begin{array}{l}\text { hexanal, } 5 \% \\
\text { hexanal, } 10 \%\end{array}$ \\
\hline MS, $1 \%$ & MS, $1 \%$ & IAA, $1 \%$ \\
\hline MS 5\% & MS, $5 \%$ & MS, $1 \%$ \\
\hline
\end{tabular}

Figure 7. Odor ranking changes for specific odorants following odor exposure. $\boldsymbol{A}$, Response rank for each odor calculated on a cell-by-cell basis. Odorants at $1 \%$ concentration displayed. $\boldsymbol{B}--\boldsymbol{D}$, Response rank for multiple concentrations of MS (B), IAA (C), and hexanal $(\boldsymbol{D})$. $\boldsymbol{E}$, Table of significant differences in odorant ranks for each group comparison. Gray asterisk, statistically significant difference between mint and control groups; blue asterisk, statistically significant difference between hexanal and control; red asterisk, statistically significant difference between hexanal and mint. 
Table 5. Comparison of odor ranks

\begin{tabular}{|c|c|c|c|c|c|c|}
\hline $\begin{array}{l}\text { Comparison } \\
\text { Response rank }\end{array}$ & Test & $p$ value & Significant & $\begin{array}{l}\text { Median } \\
\text { control (C) } \\
\mathbf{C} ; \mathbf{N}=\mathbf{2 2 5}\end{array}$ & $\begin{array}{l}\text { Median } \\
\text { mint (M) } \\
\mathbf{M} ; \mathbf{N}=\mathbf{2 6 8}\end{array}$ & $\begin{array}{l}\text { Median } \\
\text { hexanal }(\mathrm{H}) \\
\mathbf{H} ; \mathbf{N}=\mathbf{3 6 9}\end{array}$ \\
\hline AP all groups & Kruskal--Wallis & $<0.0001$ & Yes & 5 & 4 & 6 \\
\hline AP; $C$ vs $M$ & Dunn's & 0.417 & No & 5 & 4 & \\
\hline AP; C vs H & Dunn's & 0.0002 & Yes & 5 & & 6 \\
\hline AP; H vs $M$ & Dunn's & $<0.0001$ & Yes & & 4 & 6 \\
\hline EB all groups & Kruskal--Wallis & 0.0176 & Yes & 10 & 10 & 11 \\
\hline EB; C vs M & Dunn's & 0.2086 & No & 10 & 10 & \\
\hline EB; C vs H & Dunn's & 0.0138 & Yes & 10 & & 11 \\
\hline EB; $H$ vs $M$ & Dunn's & $>0.9999$ & No & & 10 & 11 \\
\hline Hexanal $1 \%$; all groups & Kruskal--Wallis & $<0.0001$ & Yes & 10 & 10 & 12 \\
\hline Hexanal $1 \%$; C vs M & Dunn's & $>0.9999$ & No & 10 & 10 & \\
\hline Hexanal $1 \%$; C vs H & Dunn's & $<0.0001$ & Yes & 10 & & 12 \\
\hline Hexanal $1 \%$; H vs M & Dunn's & $<0.0001$ & Yes & & 10 & 12 \\
\hline Hexanone; all groups & Kruskal--Wallis & $<0.0001$ & Yes & 13 & 11 & 11 \\
\hline Hexanone; C vs $\mathbf{M}$ & Dunn's & $<0.0001$ & Yes & 13 & 11 & \\
\hline Hexanone; C vs H & Dunn's & $<0.0001$ & Yes & 13 & & 11 \\
\hline Hexanone; H vs M & Dunn's & 0.0001 & Yes & & 11 & 11 \\
\hline IAA $1 \%$ all groups & Kruskal--Wallis & $<0.0001$ & Yes & 9 & 6 & 7 \\
\hline IAA $1 \%$; C vs $M$ & Dunn's & $<0.0001$ & Yes & 9 & 6 & \\
\hline IAA $1 \%$; C vs H & Dunn's & 0.0004 & Yes & 9 & & 7 \\
\hline IAA 1\%; H vs M & Dunn's & 0.0065 & Yes & & 6 & 7 \\
\hline MS $1 \%$ all groups & Kruskal--Wallis & $<0.0001$ & Yes & 5 & 3 & 3 \\
\hline MS $1 \%$; C vs M & Dunn's & $<0.0001$ & Yes & 5 & 3 & \\
\hline MS $1 \%$; C vs H & Dunn's & $<0.0001$ & Yes & 5 & & 3 \\
\hline MS $1 \% ; H$ vs M & Dunn's & 0.0391 & Yes & & 3 & 3 \\
\hline PA all groups & Kruskal--Wallis & $<0.0001$ & Yes & 4 & 5 & 7 \\
\hline PA; C vs M & Dunn's & $<0.0001$ & Yes & 4 & 5 & \\
\hline PA; C vs H & Dunn's & $<0.0001$ & Yes & 4 & & 7 \\
\hline PA; $H$ vs $M$ & Dunn's & 0.0908 & No & & 5 & 7 \\
\hline THA all groups & Kruskal--Wallis & 0.0028 & Yes & 5 & 5 & 4 \\
\hline THA; C vs M & Dunn's & $>0.9999$ & No & 5 & 5 & \\
\hline THA; C vs H & Dunn's & 0.0234 & Yes & 5 & & 4 \\
\hline THA; H vs M & Dunn's & 0.0071 & Yes & & 5 & 4 \\
\hline MS 5\%; all groups & Kruskal--Wallis & $<0.0001$ & Yes & 4 & 6 & 5 \\
\hline MS 5\%; C vs M & Dunn's & $<0.0001$ & Yes & 4 & 6 & \\
\hline MS 5\%; C vs H & Dunn's & 0.0001 & Yes & 4 & & 5 \\
\hline MS 5\%; H vs M & Dunn's & 0.4328 & No & & 6 & 5 \\
\hline MS $10 \%$; all groups & Kruskal--Wallis & 0.0731 & No & 5 & 5 & 4 \\
\hline MS $10 \%$; C vs M & Dunn's & $>0.9999$ & No & 5 & 5 & \\
\hline MS 10\%; C vs H & Dunn's & 0.1503 & No & 5 & & 4 \\
\hline MS $10 \% ; H$ vs $M$ & Dunn's & 0.1864 & No & & 5 & 4 \\
\hline IAA 5\%; all groups & Kruskal--Wallis & 0.1561 & No & 7 & 7 & 6 \\
\hline IAA $5 \% ; C$ vs $M$ & Dunn's & 0.3965 & No & 7 & 7 & \\
\hline IAA $5 \%$; C vs H & Dunn's & 0.1912 & No & 7 & & 6 \\
\hline IAA 5\%; H vs M & Dunn's & $>0.9999$ & No & & 7 & 6 \\
\hline IAA $10 \%$; all groups & Kruskal--Wallis & 0.3245 & No & 10 & 9 & 9 \\
\hline IAA $10 \% ; C$ vs M & Dunn's & 0.6739 & No & 10 & 9 & \\
\hline IAA $10 \%$; C vs H & Dunn's & 0.4643 & No & 10 & & 9 \\
\hline IAA $10 \% ; H$ vs M & Dunn's & $>0.9999$ & No & & 9 & 9 \\
\hline Hexanal $5 \%$; all groups & Kruskal--Wallis & $<0.0001$ & Yes & 12 & 12 & 12 \\
\hline Hexanal $5 \%$; C vs M & Dunn's & $>0.9999$ & No & 12 & 12 & \\
\hline Hexanal $5 \%$; C vs H & Dunn's & 0.0012 & Yes & 12 & & 12 \\
\hline Hexanal $5 \%$; H vs $\mathbf{M}$ & Dunn's & $<0.0001$ & Yes & & 12 & 12 \\
\hline Hexanal $10 \%$; all groups & Kruskal--Wallis & $<0.0001$ & Yes & 9 & 12 & 9 \\
\hline Hexanal $10 \%$; C vs $M$ & Dunn's & $<0.0001$ & Yes & 9 & 12 & \\
\hline Hexanal $10 \%$; C vs H & Dunn's & 0.7317 & No & 9 & & 9 \\
\hline Hexanal $10 \%$; H vs $\mathbf{M}$ & Dunn's & $<0.0001$ & Yes & & 12 & 9 \\
\hline
\end{tabular}

Statistical test results of odor ranks between control, mint-, and hexanal-exposed groups. Data shown in Figure 7.

tal odor enrichment and acute habituation (Wilson et al., 1985, 1987; Kato et al., 2012). Key differences between our experiments and this previous work include the tim- ing, duration, and method of odor exposure, suggesting that exposure context can modulate the effects of sensory experience on the OB. It was previously observed 
Table 6. Statistical values

\section{Statistical values \\ For all multiple comparisons tests, reported $p$ is adjusted $p$ value \\ Figure 2}

Distribution of responses; all groups; $p=6.65 \mathrm{E}-199$

Distribution of responses; $\mathrm{C}$ vs $\mathrm{M} ; \mathrm{p}$ approximates 0

Distribution of responses; $\mathrm{C}$ vs $\mathrm{H} ; p$ approximates 0

Distribution of responses; $\mathrm{H}$ vs $\mathrm{M} ; \mathrm{p}$ approximates 0

Figure 3

Excitation amplitude; IAA 10\%; all groups; $p<0.0001$

Excitation amplitude; IAA 10\%; C (med: 0.216) vs M (0.3547); $p<0.0001$

Excitation amplitude; IAA 10\%; C vs H (med: 0.3697); $p<0.0001$

Excitation amplitude; IAA 10\%; $\mathrm{H}$ vs $\mathrm{M} ; p=0.0842$

Excitation amplitude; IAA 1\%; all groups; $p<0.0001$

Excitation amplitude; IAA 1\%; C (med: 0.2018) vs $\mathrm{M}(0.2389) ; p=0.0656$

Excitation amplitude; IAA 1\%; C vs $\mathrm{H}(0.3306) ; p<0.0001$

Excitation amplitude; IAA $1 \% ; \mathrm{H}$ vs $\mathrm{M} ; p=0.0001$

Excitation amplitude; AP; all groups; $p<0.0001$

Excitation amplitude; AP; C (med: 0.1081) vs M (0.1837); $p<0.0001$

Excitation amplitude; AP; C vs H (med: 0.2822); $p<0.0001$

Excitation amplitude; AP; $\mathrm{H}$ vs $\mathrm{M} ; \mathrm{p}<0.0001$

Excitation amplitude; MS 10\%; all groups; $p<0.0001$

Excitation amplitude; MS 10\%; C (med: 0.1026) vs M (0.1961); $p<0.0001$

Excitation amplitude; MS 10\%; C vs H (med: 0.2566); $p<0.0001$

Excitation amplitude; MS 10\%; $\mathrm{H}$ vs $\mathrm{M} ; p=0.0022$

Excitation amplitude; IAA 5\%; all groups; $p<0.0001$

Excitation amplitude; IAA 5\%; C (med: 0.1404) vs M (0.2386); $p<0.0001$

Excitation amplitude; IAA 5\%; C vs $\mathrm{H}$ (med: 0.2973); $p<0.0001$

Excitation amplitude; IAA 5\%; H vs M; $p=0.0022$

Excitation amplitude; Hexanal 1\%; all groups; $p<0.0001$

Excitation amplitude; Hexanal 1\%; C (med: 0.2409) vs $\mathrm{M}(0.3421) ; p<0.0001$

Excitation amplitude; Hexanal 1\%; C vs H (med: 0.4718 ); $p<0.0001$

Excitation amplitude; Hexanal $1 \% ; \mathrm{H}$ vs $\mathrm{M} ; p=0.0001$

Excitation amplitude; EB; all groups; $p<0.0001$

Excitation amplitude; EB; C (med: 0.2262) vs M (0.3254); $p<0.0001$

Excitation amplitude; EB; C vs H (0.3204); $p<0.0001$

Excitation amplitude; EB; $\mathrm{H}$ vs $\mathrm{M} ; p=0.5796$

Excitation amplitude; MS 1\%; all groups; $p<0.0001$

Excitation amplitude; MS 1\%; C (med: 0.1167$)$ vs M $(0.1641) ; p=0.0027$

Excitation amplitude; MS 1\%; C vs H (med: 0.1933); $p<0.0001$

Excitation amplitude; MS 1\%; $\mathrm{H}$ vs $\mathrm{M} ; p=0.0224$

Excitation amplitude; PA; all groups; $p<0.0001$

Excitation amplitude; PA; C (med: 0.0733) vs M (0.2004); $p<0.0001$

Excitation amplitude; PA; C vs $\mathrm{H}$ (med: 0.2511); $p<0.0001$

Excitation amplitude; PA; $\mathrm{H}$ vs $\mathrm{M} ; p=0.0224$

Excitation amplitude; MS 5\%; all groups; $p<0.0001$

Excitation amplitude; MS 5\%; C (med: 0.0777) vs M (0.1796); $p<0.0001$

Excitation amplitude; MS 5\%; C vs H (med: 0.2503); $p<0.0001$

Excitation amplitude; MS 5\%; $\mathrm{H}$ vs $\mathrm{M} ; \mathrm{p}=0.6994$

Excitation amplitude; Hexanone; all groups; $p<0.0001$

Excitation amplitude; Hexanone; $\mathrm{C}$ (med: 0.3185$)$ vs $\mathrm{M}(0.4161) ; p<0.0001$

Excitation amplitude; Hexanone; C vs $\mathrm{H}$ (med: 0.421 ); $p<0.0001$

Excitation amplitude; Hexanone; $\mathrm{H}$ vs $\mathrm{M} ; p=0.6994$

Excitation amplitude; Hexanal 10\%; all groups; $p<0.0001$

Excitation amplitude; Hexanal 10\%; C (med: 0.2438) vs M (0.3768); $p<0.0001$

Excitation amplitude; Hexanal 10\%; C vs H (med: 0.3778); $p<0.0001$

Excitation amplitude; Hexanal $10 \% ; \mathrm{H}$ vs $\mathrm{M} ; p=0.9842$

Excitation amplitude; THA; all groups; $p<0.0001$

Excitation amplitude; THA; C (med: 0.1171$)$ vs $\mathrm{M}(0.2183) ; p<0.0001$

Excitation amplitude; THA; C vs $\mathrm{H}$ (med: 0.2415); $p<0.0001$

Excitation amplitude; THA; $\mathrm{H}$ vs $\mathrm{M} ; p=0.2338$

Excitation amplitude; Hexanal 5\%; all groups; $p<0.0001$

Excitation amplitude; Hexanal 5\%; C (med: 0.2758) vs M (0.3534); $p=0.0001$

Excitation amplitude; Hexanal 5\%; C vs H (med: 0.5212); $p<0.0001$

Excitation amplitude; Hexanal $5 \%$; $\mathrm{H}$ vs $\mathrm{M} ; \mathrm{p}<0.0001$

Figure 4, concentration comparisons

Control group

Excitation amplitude; MS; all conc.; $p=0.0586$

Excitation amplitude; MS; $1 \%$ (med: 0.1167 ) vs 5\% (0.0777); $p=0.0454$

Excitation amplitude; MS; $1 \%$ vs $10 \%$ (med: 0.1026 ); $p=0.4478$

Excitation amplitude; MS; $5 \%$ vs $10 \% ; p=0.4695$

Excitation amplitude; IAA; all conc.; $p<0.0001$

Excitation amplitude; IAA; $1 \%$ (med: 0.2018 ) vs $5 \%(0.1404) ; p=0.0027$

Excitation amplitude; IAA; $1 \%$ vs $10 \%$ (med: 0.216 ); $p=0.6607$

Excitation amplitude; IAA; $5 \%$ vs $10 \% ; p=0.0001$
Data structure

Type of test

Kruskal--Wallis

Non-norma

Non-norma

Non-normal

Non-norma

Non-normal

Non-normal

Non-normal

Non-normal

Non-norma

Non-normal

Non-normal

Non-norma

Non-normal

Non-normal

Non-normal

Non-normal

Non-norma

Non-normal

Non-norma

Non-normal

Non-normal

Non-norma

Non-normal

Non-norma

Non-normal

Non-normal

Non-norma

Non-normal

Non-normal

Non-normal

Non-normal

Non-norma

Non-normal

Non-normal

Non-normal

Non-norma

Non-normal

Non-normal

Non-norma

Non-norma

Non-normal

Non-norma

Non-normal

Non-normal

Non-normal

Non-normal

Non-norma

Non-norma

Non-normal

Non-norma

Non-norma

Non-normal

Non-norma

Non-normal

Non-normal

Non-norma

Non-normal

Non-norma

Non-normal

Non-norma

Non-normal

Non-norma

Non-normal

Non-norma

Non-normal

Non-normal

Non-normal

Non-norma

Non-normal

Non-norma
Kruskal-
Tukey's

Tukey's

Tukey's

Kruskal--Wallis

Tukey's

Tukey's

Tukey's

Kruskal--Wallis

Tukey's

Tukey's

Tukey's

Kruskal--Wallis

Tukey's

Tukey's

Tukey's

Kruskal--Wallis

Tukey's

Tukey's

Tukey's

Kruskal--Wallis

Tukey's

Tukey's

Tukey's

Kruskal--Wallis

Tukey's

Tukey's

Tukey's

Kruskal--Wallis

Tukey's

Tukey's

Tukey's

Kruskal--Wallis

Tukey's

Tukey's

Tukey's

Kruskal--Wallis

Tukey's

Tukey's

Tukey's

Kruskal--Wallis

Tukey's

Tukey's

Tukey's

Kruskal--Wallis

Tukey's

Tukey's

Tukey's

Kruskal--Wallis

Tukey's

Tukey's

Tukey's

Kruskal--Wallis

Tukey's

Tukey's

Tukey's

Kruskal--Wallis

Tukey's

Tukey's

Tukey's

Kruskal--Wallis

Tukey's

Tukey's

Tukey's

Kruskal--Wallis

Tukey's

Tukey's

Tukey's 
Table 6. Continued

Statistical values
Excitation amplitude; hexanal; all conc.; $p=0.0214$

Excitation amplitude; hexanal; $1 \%$ (med: 0.2409$)$ vs $5 \%(0.2758) ; p=0.1412$

Excitation amplitude; hexanal; $1 \%$ vs $10 \%$ (med: 0.2438 ); $p=0.6965$

Excitation amplitude; hexanal; $5 \%$ vs $10 \% ; p=0.0189$

Excitation amplitude; MS; all conc.; $p=0.206$

Excitation amplitude; MS; $1 \%$ (med: 0.1641 ) vs $5 \%(0.1796) ; p=0.0179$

Excitation amplitude; MS; $1 \%$ vs $10 \%$ (med: 0.1961 ); $p=0.1441$

Excitation amplitude; MS; $5 \%$ vs $10 \% ; p=0.6787$

Excitation amplitude; IAA; all conc.; $p<0.0001$

Excitation amplitude; IAA; $1 \%$ (med: 0.2389) vs 5\% (0.2386); $p=0.9919$

Excitation amplitude; IAA; $1 \%$ vs $10 \%$ (med: 0.3547 ); $p=0.0001$

Excitation amplitude; IAA; $5 \%$ vs $10 \% ; p=0.0001$

Excitation amplitude; hexanal; all conc.; $p=0.3426$

Excitation amplitude; hexanal; $1 \%$ (med: 0.3421$)$ vs $5 \%(0.3534) ; p=0.6541$

Excitation amplitude; hexanal; $1 \%$ vs $10 \%$ (med: 0.3768 ); $p=0.3137$

Excitation amplitude; hexanal; $5 \%$ vs $10 \% ; p=0.8335$

Hexanal group

Excitation amplitude; MS; all conc.; $p=0.0184$

Excitation amplitude; MS; $1 \%$ (med: 0.1933 ) vs $5 \%(0.2503) ; p=0.0136$

Excitation amplitude; MS; $1 \%$ vs $10 \%$ (med: 0.2566 ); $p=0.2275$

Excitation amplitude; MS; $5 \%$ vs $10 \% ; p=0.4712$

Excitation amplitude; IAA; all conc.; $p=0.0433$

Excitation amplitude; IAA; $1 \%$ (med: 0.3306) vs 5\% (0.2973); $p=0.7292$

Excitation amplitude; IAA; $1 \%$ vs $10 \%(0.3697) ; p=0.2089$

Excitation amplitude; IAA; $5 \%$ vs $10 \% ; p=0.0382$

Excitation amplitude; hexanal; all conc.; $p<0.0001$

Excitation amplitude; hexanal; $1 \%(0.4718)$ vs $5 \%(0.5212) ; p=0.2589$

Excitation amplitude; hexanal; $1 \%$ vs $10 \%(0.3778) ; p=0.0127$

Excitation amplitude; hexanal; $5 \%$ vs $10 \% ; p<0.0001$

Figure 5

Ratio of excitatory events; all odors; $p<0.0001$

Ratio of excitatory events; all odors: C (med: 0.88$)$ vs $\mathrm{M}(0.9235) ; p<0.0001$

Ratio of excitatory events; all odors: $\mathrm{C}$ vs $\mathrm{H}$ (med: 0.9377$) ; p<0.0001$

Ratio of excitatory events; all odors: $\mathrm{H}$ vs $\mathrm{M} ; p=0.1313$

Ratio of activating odors; all groups; $p<0.0001$

Ratio of activating odors; C (med: 13) vs, M (14); $p<0.0001$

Ratio of activating odors; $\mathrm{C}$ vs $\mathrm{H}$ (med: 14$) ; p<0.0001$

Ratio of activating odors; $\mathrm{H}$ vs $\mathrm{M} ; \mathrm{p}>0.9999$

Figure 6

Successes; AP; all groups; $p<0.0001$

Successes; AP; C (med: 0.75) vs M (1); $p<0.0001$

Successes; AP; C vs H (med: 1 ); $p<0.0001$

Successes; AP; $\mathrm{H}$ vs $\mathrm{M} ; p=0.0029$

Successes; EB; all groups; $p=0.0181$

Successes; EB; C (med: 1 ) vs M (1); $p=0.0151$

Successes; EB; C vs H (1); $p=0.5476$

Successes; EB; $\mathrm{H}$ vs $\mathrm{M} ; p=0.2351$

Successes; Hexanal 1\%; all groups; $p=0.0596$

Successes; Hexanal 1\%; C (med: 1) vs M (med: 1$) ; p=0.7821$

Successes; Hexanal 1\%; C vs H (med: 1); $p=0.0562$

Successes; Hexanal $1 \%$; $\mathrm{H}$ vs $\mathrm{M} ; \mathrm{p}=0.6464$

Successes; Hexanone; all groups; $p=0.1165$

Successes; Hexanone; C (med: 1) vs M (1); $p=0.1277$

Successes; Hexanone; C vs H (1); $p=0.3668$

Successes; Hexanone; $H$ vs $M ; p>0.9999$

Successes; IAA 1\%; all groups; $p=0.0902$

Successes; IAA 1\%; C (med: 1 ) vs M (1); $p=0.4431$

Successes; IAA 1\%; C vs H (1); $p=0.0867$

Successes; IAA 1\%; H vs $M ; p>0.9999$

Successes; MS 1\%; all groups; $p=0.0139$

Successes; MS 1\%; C (med: 0.75) vs M (1); $p=0.0621$

Successes; MS 1\%; C vs H (1); $p=0.0144$

Successes; MS 1\%; H vs M; $p>0.9999$

Successes; PA; all groups; $p<0.0001$

Successes; PA; C (med: 0.75 ) vs M (1); $p<0.0001$

Successes; PA; C vs H (1); $p<0.0001$

Successes; PA; $\mathrm{H}$ vs $\mathrm{M} ; p=0.0019$

Successes; THA; all groups; $p<0.0001$

Successes; THA; C (med: 0.75); vs M (1); $p<0.0001$

Successes; THA; C vs H (1); $p<0.0001$

Successes; THA; H vs $M ; p=0.9588$

Successes; MS 5\%; all groups; $p<0.0001$
Data structure

Non-normal

Non-normal

Non-normal

Non-normal

Non-normal

Non-normal

Non-normal

Non-normal

Non-normal

Non-normal

Non-normal

Non-normal

Non-normal

Non-normal

Non-normal

Non-normal

Non-normal

Non-normal

Non-normal

Non-normal

Non-normal

Non-normal

Non-normal

Non-normal

Non-normal

Non-normal

Non-normal

Non-normal

Normal

Normal

Normal

Normal

Non-normal

Non-normal

Non-normal

Non-normal

Non-normal

Non-normal

Non-normal

Non-normal

Non-normal

Non-normal

Non-normal

Non-normal

Non-normal

Non-normal

Non-normal

Non-normal

Non-normal

Non-normal

Non-normal

Non-normal

Non-normal

Non-normal

Non-normal

Non-normal

Non-normal

Non-normal

Non-normal

Non-normal

Non-normal

Non-normal

Non-normal

Non-normal

Non-normal

Non-normal

Non-normal

Non-normal

Non-normal
Type of test

Kruskal--Wallis

Tukey's

Tukey's

Tukey's

Kruskal--Wallis

Tukey's

Tukey's

Tukey's

Kruskal--Wallis

Tukey's

Tukey's

Tukey's

Kruskal--Wallis

Tukey's

Tukey's

Tukey's

Kruskal--Wallis

Tukey's

Tukey's

Tukey's

Kruskal--Wallis

Tukey's

Tukey's

Tukey's

Kruskal--Wallis

Tukey's

Tukey's

Tukey's

ANOVA

Tukey's

Tukey's

Tukey's

Kruskal--Wallis

Dunn's

Dunn's

Dunn's

Kruskal--Wallis

Dunn's

Dunn's

Dunn's

Kruskal--Wallis

Dunn's

Dunn's

Dunn's

Kruskal--Wallis

Dunn's

Dunn's

Dunn's

Kruskal--Wallis

Dunn's

Dunn's

Dunn's

Kruskal--Wallis

Dunn's

Dunn's

Dunn's

Kruskal--Wallis

Dunn's

Dunn's

Dunn's

Kruskal--Wallis

Dunn's

Dunn's

Dunn's

Kruskal--Wallis

Dunn's

Dunn's

Dunn's

Kruskal--Wallis 
Table 6. Continued

\section{Statistical values}

Successes; MS 5\%; C (med: 0.75) vs M (1); $p<0.0001$

Successes; MS 5\%; C vs H (med: 1 ); $p<0.0001$

Successes; MS 5\%; H vs M; $p>0.9999$

Successes; MS 10\%; all groups; $p<0.0001$

Successes; MS 10\%; C (med: 0.75) vs M (1); $p<0.0001$

Successes; MS 10\%; C vs H (med: 1 ); $p<0.0001$

Successes; MS 10\%; H vs M; $p>0.9999$

Successes; Hexanal 5\%; all groups; $p=0.0016$

Successes; Hexanal 5\%; C (med: 1 ) vs M (1); $p=0.4815$

Successes; Hexanal 5\%; C vs H (med: 1); $p=0.0014$

Successes; Hexanal $5 \%$; $\mathrm{H}$ vs $\mathrm{M} ; p=0.1031$

Successes; Hexanal 10\%; all groups; $p=0.0001$

Successes; Hexanal 10\%; C (med: 1) vs M (1); $p=0.0001$

Successes; Hexanal 10\%; C vs H (med: 1); $p=0.0029$

Successes; Hexanal 10\%; $\mathrm{H}$ vs $\mathrm{M} ; p=0.81$

Successes; IAA 5\%; all groups; $p<0.0001$

Successes; IAA 5\%; C (med: 1) vs M (1); $p=0.0026$

Successes; IAA $5 \%$; C vs H (med: 1 ); $p<0.0001$

Successes; IAA $5 \%$; $H$ vs $M ; p=0.4956$

Successes; IAA 10\%; all groups; $p=0.0007$

Successes; IAA 10\%; C (med: 1) vs $M(1) ; p=0.0007$

Successes; IAA 10\%; C vs H (med: 1$) ; p=0.01$

Successes; IAA $10 \%$; $\mathrm{H}$ vs $\mathrm{M} ; p=0.8374$

Successes; All odors combined; all groups; $p<0.0001$

Successes; All odors combined; C (med: 1) vs M (1); $p<0.0001$

Successes; All odors combined; $\mathrm{C}$ vs H (med: 1 ); $p<0.0001$

Successes; All odors combined; $\mathrm{H}$ vs $\mathrm{M}, p=0.0836$

Figure 7

Comparison of ranks; AP; all groups; $p<0.0001$

Comparison of ranks; AP; C (med: 5 ) vs M (4); $p=0.4176$

Comparison of ranks; AP; $\mathrm{C}$ vs $\mathrm{H}$ (med: 6 ); $p=0.0002$

Comparison of ranks; $\mathrm{AP} ; \mathrm{H}$ vs $\mathrm{M} ; \mathrm{p}<0.0001$

Comparison of ranks; EB; all groups; $p=0.0176$

Comparison of ranks; EB; C (med: 10) vs $\mathrm{M}(10) ; p=0.2086$

Comparison of ranks; EB; C vs $\mathrm{H}$ (med: 11$) ; p=0.0138$

Comparison of ranks; $\mathrm{EB} ; \mathrm{H}$ vs $\mathrm{M} ; \mathrm{p}>0.9999$

Comparison of ranks; Hex $1 \%$; all groups; $p<0.0001$

Comparison of ranks; Hex 1\%; C (med: 10) vs M (10); $p>0.9999$

Comparison of ranks; Hex 1\%; C vs $\mathrm{H}$ (med: 12); $p<0.0001$

Comparison of ranks; Hex $1 \% ; \mathrm{H}$ vs $\mathrm{M} ; p<0.0001$

Comparison of ranks; Hexanone; all groups; $p<0.0001$

Comparison of ranks; Hexanone; C (med: 13) vs $\mathrm{M}(11) ; p<0.0001$

Comparison of ranks; Hexanone; C vs H (med: 11 ); $p<0.0001$

Comparison of ranks; Hexanone; $\mathrm{H}$ vs $\mathrm{M} ; p=0.0001$

Comparison of ranks; IAA 1\%; all groups; $p<0.0001$

Comparison of ranks; IAA 1\%; C (med: 9) vs M (6); $p<0.0001$

Comparison of ranks; IAA 1\%; C vs $\mathrm{H}$ (med: 7 ); $p=0.0004$

Comparison of ranks; IAA $1 \% ; \mathrm{H}$ vs $\mathrm{M} ; p=0.0065$

Comparison of ranks; MS 1\%; all groups; $p<0.0001$

Comparison of ranks; MS 1\%; C (med: 5) vs M (3); $p<0.0001$

Comparison of ranks; MS 1\%; C vs $\mathrm{H}$ (med: 3 ); $p<0.0001$

Comparison of ranks; MS $1 \%$; $\mathrm{H}$ vs $\mathrm{M} ; p=0.0391$

Comparison of ranks; PA; all groups; $p<0.0001$

Comparison of ranks; PA; C (med: 4) vs $\mathrm{M}(5) ; p<0.0001$

Comparison of ranks; PA; C vs $\mathrm{H}$ (med: 7 ); $p<0.0001$

Comparison of ranks; PA; $\mathrm{H}$ vs $\mathrm{M} ; p=0.0908$

Comparison of ranks; THA; all groups; $p=0.0028$

Comparison of ranks; THA; C (med: 5) vs M (5); $p>0.9999$

Comparison of ranks; THA; $\mathrm{C}$ vs $\mathrm{H}$ (med: 4 ); $p=0.0234$

Comparison of ranks; THA; $\mathrm{H}$ vs $\mathrm{M} ; p=0.0071$

Comparison of ranks; MS 5\%; all groups; $p<0.0001$

Comparison of ranks; MS 5\%; C (med: 4) vs M (6); $p<0.0001$

Comparison of ranks; MS 5\%; C vs $\mathrm{H}$ (med: 5 ); $p=0.0001$

Comparison of ranks; MS $5 \% ; \mathrm{H}$ vs $\mathrm{M} ; p=0.4328$

Comparison of ranks; MS 10\%; all groups; $p=0.0731$

Comparison of ranks; MS 10\%; C (med: 5) vs M (5); $p>0.999$

Comparison of ranks; MS 10\%; C vs H (4); $p=0.1503$

Comparison of ranks; MS $10 \%$; $\mathrm{H}$ vs $\mathrm{M} ; p=0.1864$

Comparison of ranks; IAA 5\%; all groups; $p=0.1561$

Comparison of ranks; IAA 5\%; C (med: 7) vs $M(7) ; p=0.3965$

Comparison of ranks; IAA 5\%; C vs H (med: 6$) ; p=0.1912$

Comparison of ranks; IAA 5\%; $\mathrm{H}$ vs $\mathrm{M} ; \mathrm{p}>0.9999$

Comparison of ranks; IAA $10 \%$; all groups; $p=0.3245$
Data structure

Non-normal

Non-normal

Non-normal

Non-normal

Non-normal

Non-normal

Non-normal

Non-normal

Non-normal

Non-normal

Non-normal

Non-normal

Non-normal

Non-normal

Non-normal

Non-normal

Non-normal

Non-normal

Non-normal

Non-normal

Non-normal

Non-normal

Non-normal

Non-normal

Non-normal

Non-normal

Non-normal

Non-normal

Non-normal

Non-normal

Non-normal

Non-normal

Non-normal

Non-normal

Non-normal

Non-normal

Non-normal

Non-normal

Non-normal

Non-normal

Non-normal

Non-normal

Non-normal

Non-normal

Non-normal

Non-normal

Non-normal

Non-normal

Non-normal

Non-normal

Non-normal

Non-normal

Non-normal

Non-normal

Non-normal

Non-normal

Non-normal

Non-normal

Non-normal

Non-normal

Non-normal

Non-normal

Non-normal

Non-normal

Non-normal

Non-normal

Non-normal

Non-normal

Non-normal

Non-normal

Non-normal

Non-normal
Type of test

Dunn's

Dunn's

Dunn's

Kruskal--Wallis

Dunn's

Dunn's

Dunn's

Kruskal--Wallis

Dunn's

Dunn's

Dunn's

Kruskal--Wallis

Dunn's

Dunn's

Dunn's

Kruskal--Wallis

Dunn's

Dunn's

Dunn's

Kruskal--Wallis

Dunn's

Dunn's

Dunn's

Kruskal--Wallis

Dunn's

Dunn's

Dunn's

Kruskal--Wallis

Dunn's

Dunn's

Dunn's

Kruskal--Wallis

Dunn's

Dunn's

Dunn's

Kruskal--Wallis

Dunn's

Dunn's

Dunn's

Kruskal--Wallis

Dunn's

Dunn's

Dunn's

Kruskal--Wallis

Dunn's

Dunn's

Dunn's

Kruskal--Wallis

Dunn's

Dunn's

Dunn's

Kruskal--Wallis

Dunn's

Dunn's

Dunn's

Kruskal--Wallis

Dunn's

Dunn's

Dunn's

Kruskal--Wallis

Dunn's

Dunn's

Dunn's

Kruskal--Wallis

Dunn's

Dunn's

Dunn's

Kruskal--Wallis

Dunn's

Dunn's

Dunn's

Kruskal--Wallis 
Table 6. Continued

\begin{tabular}{|c|c|c|c|}
\hline Statistical values & Data structure & Type of test & Power \\
\hline Comparison of ranks; IAA 10\%; C (med: 10$)$ vs $\mathrm{M}(9) ; p=0.6739$ & Non-normal & Dunn's & \\
\hline Comparison of ranks; IAA $10 \%$; C vs H (med: 9 ); $p=0.4643$ & Non-normal & Dunn's & \\
\hline Comparison of ranks; IAA $10 \% ; \mathrm{H}$ vs $\mathrm{M} ; p>0.999$ & Non-normal & Dunn's & \\
\hline Comparison of ranks; Hex 5\%; all groups; $p<0.0001$ & Non-normal & Kruskal--Wallis & \\
\hline Comparison of ranks; Hex 5\%; C (med: 12) vs M (12); $p>0.9999$ & Non-normal & Dunn's & \\
\hline Comparison of ranks; Hex $5 \%$; C vs H (med: 12$) ; p=0.0012$ & Non-normal & Dunn's & \\
\hline Comparison of ranks; Hex 5\%; H vs $\mathrm{M} ; p<0.0001$ & Non-normal & Dunn's & \\
\hline Comparison of ranks; Hex 10\%; all groups; $p<0.0001$ & Non-normal & Kruskal--Wallis & \\
\hline Comparison of ranks; Hex 10\%; C (med: 9 ) vs M (12); $p<0.0001$ & Non-normal & Dunn's & \\
\hline Comparison of ranks; Hex $10 \%$; C vs H (9); $p=0.7317$ & Non-normal & Dunn's & \\
\hline Comparison of ranks; Hex $10 \%$; H vs $M ; p<0.0001$ & Non-normal & Dunn's & \\
\hline \multicolumn{4}{|l|}{ Figure 8} \\
\hline Habituation; all groups; $p<0.0001$ & Non-normal & Friedman Test & Friedman statistic: 46.52 \\
\hline Habituation; Pre vs 5 min Post; $p<0.0001$ & Non-normal & Tukey's & \\
\hline Habituation; Pre vs 30 min Post; $p<0.0001$ & Non-normal & Tukey's & \\
\hline Habituation; 5 vs 30 min Post; $p>0.9999$ & Non-normal & Tukey's & \\
\hline
\end{tabular}

that prenatal and early postnatal food-based odor exposure increases the number of M/TCs associated with a glomerulus known to be activated by the conditioned odor (Liu et al., 2016). Here, we find that this exposure paradigm also induces widespread changes to odorevoked MC responses. Such changes may be the result of several mechanisms, including the timing of odor exposure during early development, the use of food-odor association in this paradigm, and/or general sensory enrichment. Further work is necessary to determine the exact mechanisms resulting in this generalized increase in MC excitability.

\section{Prenatal and early postnatal odorant exposure significantly changes excitatory odor-evoked MC responses in an odor-nonspecific way}

The lack of clear odor-specificity in changes following odor conditioning was surprising, given previous work showing specificity in anatomic changes following prenatal and early postnatal odorant exposure (Todrank et al.,
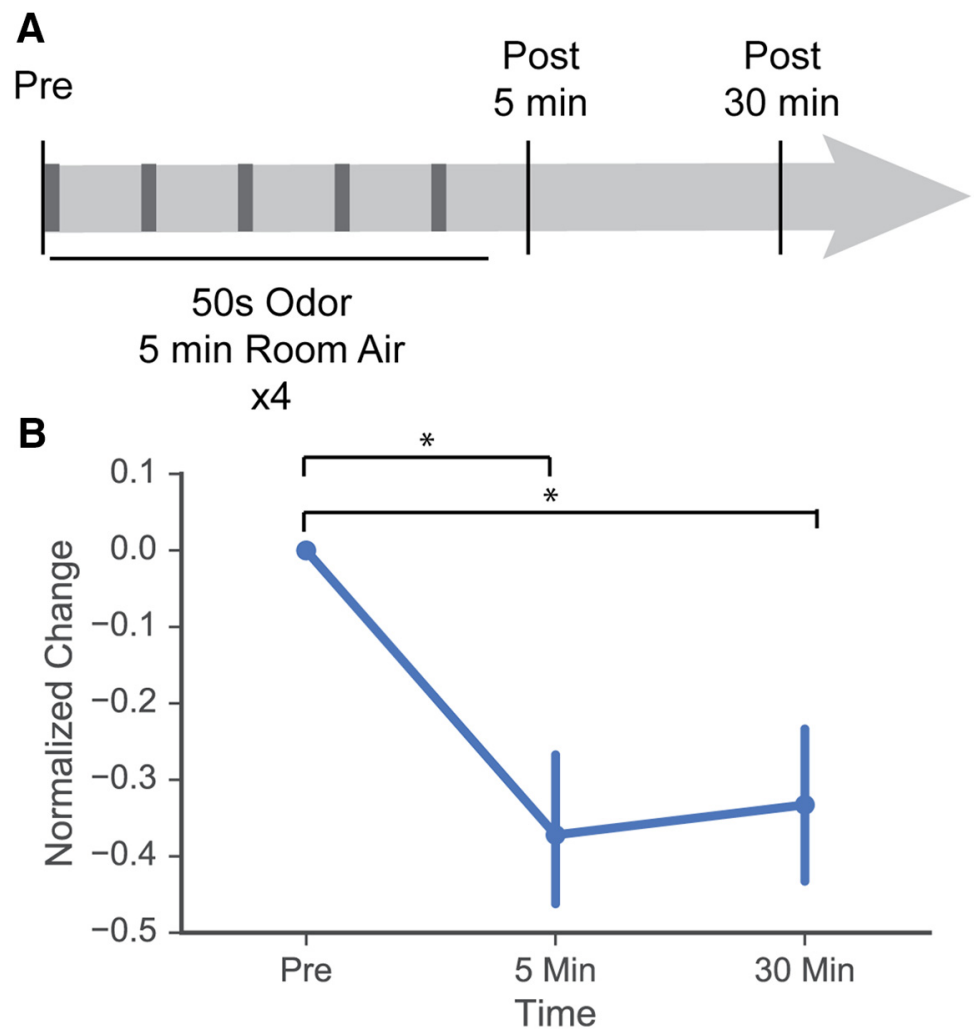

Figure 8. MCs display acute habituation following repeated short odor pulses. $\boldsymbol{A}$, Odor stimulus (hexanal at $1 \%$ concentration) was presented for $50 \mathrm{~s}$ followed by 5 min of room air, with stimulus repeated four times. MC odor-evoked response was captured before stimulus presentation, 5 min after final 50 -s odor stimulus, and 30 min after final 50 -s odor stimulus. $\boldsymbol{B}$, Normalized change in odor response between prestimulus and 5-min or 30-min poststimulus. Significant decrease in odor response was observed at both time points poststimulus; * indicates statistically significant comparison. 
2011; Liu et al., 2016), previous work showing that an early postnatal conditioning paradigm increases lateral inhibition (Geramita and Urban, 2016), and the observation that early postnatal odor conditioning results in a reduced response to conditioned but not other odors (Wilson et al., 1985). However, 2-DG maps of glomerular activation in rats (Glomerular Activity Response Archive, Michael Leon, gara.bio.uci.edu/index.jsp) show that both MS and hexanal activate a large number of potentially overlapping glomeruli on the dorsal OB surface, so it is possible that the widespread nature of the changes we observe in odor-evoked MC excitatory responses are due to the widespread activation of dorsal glomeruli by these exposure odorants. These changes may not be seen in areas of the $\mathrm{OB}$ that lack glomeruli activated by either odor. Although MS and hexanal are quite different perceptually and structurally, the lack of intuitive glomerular organization by odorant in the $\mathrm{OB}$ precludes us from knowing whether these two odorants activate very different sets of glomeruli. Further work is necessary to elucidate if these changes in $\mathrm{MC}$ response can be generalized to MCs in OB areas known to not be activated by either of these two odorants, or if odorant specific changes in excitability can be achieved with odorants known to have nonoverlapping glomerular activation maps.

Tuning curves of $\mathrm{MC}$ response also changed following mint and hexanal odorant exposure. Because there were also significant tuning curve differences between the mint- and hexanal-exposed groups for specific odorants in the stimulus panel, there may be relative changes in response rank specific to the identity of exposed odorant. MS and hexanal have different glomerular activation patterns, thus chronic odorant exposure may change the network of lateral inhibition and change odor-evoked response in overlapping but distinct ways. Use of a larger odor panel including ventral-activating odorants would help elucidate whether these changes in rank and in excitatory responses are connected to the identity of the odorant used for exposure.

In addition, there may be differences in the effect of early odorant exposure on male and female mice. Recent work suggests that OSN signaling differs between female and male mice - specifically, OSNs from female mice respond faster to odor presentation and are more broadly tuned than male OSNs (Kass et al., 2017). However, previous work by Liu et al. (2016) showed that early odorant exposure using the same paradigm as in this study changes the number of M/TCs connected to a single activated glomerulus, but these changes are not significantly different between male and female mice. In our data, we find that the distribution of odor-evoked excitatory MC responses is different between male hexanal-exposed and control mice but not between male mint-exposed and control mice. Contrastingly, there were significant differences in response distribution between female odor-exposed (both hexanal- and mint-exposed) and control mice. However, we only obtained data from one female control and two female odor-exposed animals from each group, insufficient subject number to draw strong conclusions about whether these changes in re- sponse distribution are due to interanimal variability or sexual dimorphism.

\section{Activation pattern similarity of odorant stimuli}

In this study, most cells had observed above-threshold responses to most odorants in the panel (Fig. 5E). This difference from the sparser MC response to odorants observed previously (Kato et al., 2012; Blauvelt et al., 2013; Wachowiak et al., 2013; Roland et al., 2016) could be due to (1) the high sensitivity of GCaMP6s calcium indicator, (2) the choice of odorants within the stimulus panel, (3) the use of higher odorant concentrations in our study, and (4) the use of an anesthetized preparation. In in vivo studies of visual cortical neurons, use of GCaMP6s resulted in a fivefold higher rate of detection of responding neurons than GCaMP3, suggesting that the larger proportion of observed odor-evoked responses in our data set could be partially explained by use of a more sensitive calcium indicator (Chen et al., 2013). The choice of odorants used for chronic exposure and in the odor panel was deliberately focused on dorsal OB activating odorants to visualize odor-evoked responses in the cohort of cells imaged, those on the dorsal OB surface. Thus, the composition of the stimulus panel may explain why a large proportion of cells on the dorsal OB surface showed significant odor-evoked responses to many dorsally-activating odorants in the panel.

MC activity differs significantly between the awake and the anesthetized states. Kato et al. (2012), found that the MCs of anesthetized animals are more responsive, each odorant elicits response from a larger number of MCs, and the amplitude of odor-evoked responses is also greater. They also found that experience-dependent habituation of odor-evoked MC response is dependent on odor presentation in the awake state, as brief odor presentation while under anesthesia did not result in MC response habituation. Chaudhury et al. (2010), observed that acute odorant exposure causes habituation of MC response in anesthetized animals, a finding that we replicate in Figure 8. In contrast to Kato et al. (2012), our odorant exposure paradigm consists of food-based odorant exposure throughout gestation and nursing. This paradigm has been shown to induce significant changes in both glomerulus volume and the number of M/TCs connected to single glomeruli (Todrank et al., 2011; Liu et al., 2016). Todrank et al. (2011), additionally observed that odorant exposure limited to either the gestation period or the postnatal nursing period induced an increase in glomerular volume. In this study, we do not address whether the experience-dependent changes in $\mathrm{MC}$ response can be observed following odorant exposure limited to a specific developmental period or whether these changes can be observed in the awake animal. However, given the significant anatomic changes in the $\mathrm{OB}$ observed after prenatal and early postnatal odorant exposure, we predict that we would also observe an increase in excitatory odor-evoked MC response in awake mice and that this change remains robust following exposure limited to either gestation or nursing. 


\section{Prenatal and postnatal timing of odorant exposure}

The timing of our odorant exposure paradigm may be one explanation for why we find an increase rather than a decrease in excitability following exposure. Here, we use a conditioning paradigm of constant odor exposure during both gestation and the postnatal period. Todrank et al. (2011) show that exposure during either gestation or early nursing is sufficient to significantly increase the size of activated glomeruli, while Liu et al. (2016) demonstrate that this paradigm also increases the number of M/TCs connected to a single activated glomerulus. Prenatal food-based odor exposure can produce large anatomic changes in the OB circuitry. We show that this paradigm also promotes nonspecific changes to excitatory MC odor-evoked responses; these findings contrast with previous studies of odor-evoked MC responses following both acute and chronic odor exposure. However, the majority of studies analyzing experience-dependent changes to the structure and function of the OB rely on postnatal manipulations (Benson et al., 1984; Laing, 1985; Panhuber and Laing, 1987; Saghatelyan et al., 2005; Kerr and Belluscio, 2006; Woo et al., 2006; Cavallin et al., 2010; Johnson et al., 2013; Morrison et al., 2015; Geramita and Urban, 2016). Starting exposure during gestation may trigger developmental changes distinct from those observed with postnatal odor experience.

\section{Sensory enrichment}

Generalized early postnatal sensory enrichment may be another explanation for the observed nonspecific enhanced excitatory responses. Odor deprivation during development causes significant changes to OB structure and activity. OB size, OSN activity, MC connectivity, and granule cell integration are all impacted by early nares occlusion (Benson et al., 1984; Saghatelyan et al., 2005; Cavallin et al., 2010). With regards to the anatomic effects of early postnatal chronic odor enrichment or stimulation, the consensus is less clear. A number of studies report a significant decrease in the size and density of MCs following chronic passive odor exposure (Laing, 1985; Panhuber and Laing, 1987; Woo et al., 2006; Johnson et al., 2013). However, Rosselli-Austin and Williams (1990), used scented objects in a normal cage setting to deliver chronic odor stimulation and found that mitral and granule cell numbers actually increased following neonatal odorant exposure. In addition, numbers of adult born granule cells (Rochefort et al., 2002) and dopaminergic cells (Bonzano et al., 2014) also increase following chronic postnatal odorant exposure. These results suggest that richness of the sensory environment during the neonatal period can significantly modify $\mathrm{OB}$ structure. Our work points to a general increase in MC excitability, as measured by the number and amplitude of excitatory odor-evoked responses. This generalized change could be due to sensory enrichment through odorant exposure during a critical period of OB development.

Enrichment can also modify the excitability of other sensory systems. Studies in cat visual cortex showed that rearing animals in an enriched environment increased the number of orientation selective cells, sharpened orienta- tion tuning of cells, and increased responsivity of cells to light stimuli (Beaulieu and Cynader, 1990a,b). Such changes are observed during adulthood as well, following visual enrichment, adult rats with amblyopia demonstrated improved visual acuity and reduced inhibition/ excitation balance in V1 (Baroncelli et al., 2012). Other sensory systems also demonstrate this feature, with sensory enrichment increasing excitatory responses and refinement of stimulus selectivity within the auditory and somatosensory systems (Coq and Xerri, 1998; Bourgeon et al., 2004; Engineer et al., 2004; Alwis and Rajan, 2013) This phenomenon also may be taking place in the $\mathrm{OB}$, as we observe a generalized, nonstimulus specific increase in $\mathrm{MC}$ excitatory response amplitude and number following odorant exposure.

\section{Food-associated exposure paradigm}

Lastly, food-association may contribute to the generalized increase in MC excitation. Here, we pair food with odorant. For the moth Manduca sexta, pairing repeated odor exposure with food resulted in an increase in responsive neurons while repeated odor exposure without food caused a decrease in responsive neurons (Daly et al., 2004). While these experiments were conducted in a different organism and used acute trials of odor pairing rather than the chronic odor exposure that we use, the Manduca study demonstrates that odorant context plays a role in experience-dependent modifications in response. When exposed to odorized food, mice demonstrate a distinct preference for food scented with the familiar odorant (Todrank et al., 2011; Liu et al., 2016), indicating a positive odorant association following foodbased exposure. However, Wilson et al. (1985), found that pairing odor puffs with brushing, an association with a positive or attractive context, results in a decrease of excitatory responses to presentations of the exposure odorant alone. The contrasting results from studies that use different odor exposure paradigms, reward-paired or passive, suggest that context of odor presentation could play an important role in determining how the circuit remodels anatomically and functionally following repeated or chronic odor exposure.

\section{Conclusion}

Here, we use a food-based paradigm to investigate the effects of prenatal and early postnatal odor exposure on odor-evoked responses of MCs. We find that odorant exposure heightened dorsal OB MC activity, increasing the amplitude, reliability, and the proportion of excitatory odor-evoked MC responses. We also find that odorant exposure changed the tuning curves of MCs in exposed animals. These effects were not specific to odor-evoked responses to either MS or hexanal, the odorants used for exposure. Rather, prenatal and early postnatal odorant exposure using either odorant resulted in generalized changes to $\mathrm{MC}$ responses across the dorsal $\mathrm{OB}$ and in response to all odorants in the stimulus panel. Control, hexanal-, and MS-exposed animals all demonstrated a similar decrease in odor-evoked MC responses following acute odorant habituation with hexanal, indicating that 
our paradigm of constant early odorant exposure does not fundamentally change mechanisms of habituation.

\section{References}

Alwis DS, Rajan R (2013) Environmental enrichment causes a global potentiation of neuronal responses across stimulus complexity and lamina of sensory cortex. Front Cell Neurosci 7:124. CrossRef Medline

Baroncelli L, Bonaccorsi J, Milanese M, Bonifacino T, Giribaldi F, Manno I, Cenni MC, Berardi N, Bonanno G, Maffei L, Sale A (2012) Enriched experience and recovery from amblyopia in adult rats: impact of motor, social and sensory components. Neuropharmacology 62:2388-2397. Medline

Beaulieu C, Cynader M (1990a) Effect of the richness of the environment on neurons in cat visual cortex. II. Spatial and temporal frequency characteristics. Brain Res Dev Brain Res 53:82-88.

Beaulieu C, Cynader M (1990b) Effect of the richness of the environment on neurons in cat visual cortex. I. Receptive field properties. Brain Res Dev Brain Res 53:71-81.

Benson TE, Ryugo DK, Hinds JW (1984) Effects of sensory deprivation on the developing mouse olfactory system: a light and electron microscopic, morphometric analysis. J Neurosci 4:638-653. Medline

Blauvelt DG, Sato TF, Wienisch M, Murthy VN (2013) Distinct spatiotemporal activity in principal neurons of the mouse olfactory bulb in anesthetized and awake states. Front Neural Circuits 7:46. CrossRef

Bonzano S, Bovetti S, Fasolo A, Peretto P, De Marchis S (2014) Odour enrichment increases adult-born dopaminergic neurons in the mouse olfactory bulb. Eur J Neurosci 40:3450-3457. CrossRef Medline

Bourgeon S, Xerri C, Coq J-O (2004) Abilities in tactile discrimination of textures in adult rats exposed to enriched or impoverished environments. Behav Brain Res 153:217-231. CrossRef

Bozza T, Feinstein P, Zheng C, Mombaerts P (2002) Odorant receptor expression defines functional units in the mouse olfactory system. J Neurosci 22:3033-3043. Medline

Cavallin MA, Powell K, Biju KC, Fadool DA (2010) State-dependent sculpting of olfactory sensory neurons attributed to sensory enrichment, odor deprivation, and aging. Neurosci Lett 483:90-95. CrossRef Medline

Chaudhury D, Manella L, Arellanos A, Escanilla O, Cleland TA, Linster C (2010) Olfactory bulb habituation to odor stimuli. Behav Neurosci 124:490-499. CrossRef Medline

Chen T-W, Wardill TJ, Sun Y, Pulver SR, Renninger SL, Baohan A, Schreiter ER, Kerr RA, Orger MB, Jayaraman V, Looger LL, Svoboda K, Kim DS (2013) Ultrasensitive fluorescent proteins for imaging neuronal activity. Nature 499:295-300. CrossRef Medline

Coq JO, Xerri C (1998) Environmental enrichment alters organizational features of the forepaw representation in the primary somatosensory cortex of adult rats. Exp Brain Res 121:191-204. Medline

Daly KC, Christensen TA, Lei H, Smith BH, Hildebrand JG (2004) Learning modulates the ensemble representations for odors in primary olfactory networks. Proc Natl Acad Sci USA 101:1047610481. CrossRef Medline

Dias BG, Ressler KJ (2014) Parental olfactory experience influences behavior and neural structure in subsequent generations. Nat Neurosci 17:89-96. CrossRef Medline

Engineer ND, percaccio CR, Pandya PK, Moucha R, Rathbun DL, Kilgard MP (2004) Environmental enrichment improves response strength, threshold, selectivity, and latency of auditory cortex neurons. J Neurophysiol 92:73-82. CrossRef Medline

Feinstein P, Mombaerts P (2004) A contextual model for axonal sorting into glomeruli in the mouse olfactory system. Cell 117:817831. CrossRef Medline

Geramita M, Urban NN (2016) Postnatal odor exposure increases the strength of interglomerular lateral inhibition onto olfactory bulb tufted cells. J Neurosci 36:12321-12327. CrossRef
Johnson MC, Biju KC, Hoffman J, Fadool DA (2013) Odor enrichment sculpts the abundance of olfactory bulb mitral cells. Neurosci Lett 541:173-178. CrossRef

Kass MD, Czarnecki LA, Moberly AH, McGann JP (2017) Differences in peripheral sensory input to the olfactory bulb between male and female mice. Sci Rep 7:45851. CrossRef Medline

Kato HK, Chu MW, Isaacson JS, Komiyama T (2012) Dynamic sensory representations in the olfactory bulb: modulation by wakefulness and experience. Neuron 76:962-975. CrossRef Medline

Kerr MA, Belluscio L (2006) Olfactory experience accelerates glomerular refinement in the mammalian olfactory bulb. Nat Neurosci 9:484-486. CrossRef Medline

Komiyama T, Luo L (2006) Development of wiring specificity in the olfactory system. Curr Opin Neurobiol 16:67-73. CrossRef Medline

Laing DG (1985) Prolonged exposure to an odor or deodorized air alters the size of mitral cells in the olfactory bulb. Brain Res 336:81-87. Medline

Liu A, Savya S, Urban NN (2016) Early odorant exposure increases the number of mitral and tufted cells associated with a single glomerulus. J Neurosci 36:11646-11653. CrossRef Medline

Morrison FG, Dias BG, Ressler KJ (2015) Extinction reverses olfactory fear-conditioned increases in neuron number and glomerular size. Proc Natl Acad Sci USA 112:12846-12851. CrossRef Medline

Ogg MC, Bendahamane M, Fletcher ML (2015) Habituation of glomerular responses in the olfactory bulb following prolonged odor stimulation reflects reduced peripheral input. Front Mol Neurosci 8:53.

Panhuber H, Laing DG (1987) The size of mitral cells is altered when rats are exposed to an odor from their day of birth. Dev Brain Res 431:133-140. Medline

Potter SM, Zheng C, Koos DS, Feinstein P, Fraser SE, Mombaerts P (2001) Structure and emergence of specific olfactory glomeruli in the mouse. J Neurosci 21:9713-9723. Medline

Ressler KJ, Sullivan SL, Buck LB (1994) Information coding in the olfactory system: evidence for a stereotyped and highly organized epitope map in the olfactory bulb. Cell 79:1245-1255. Medline

Rochefort C, Gheusi G, Vincent J-D, Lledo P-M (2002) Enriched odor exposure increases the number of newborn neurons in the adult olfactory bulb and improves odor memory. J Neurosci 22:26792689.

Roland B, Jordan R, Sosulski DL, Diodato A, Fukunaga I, Wickersham I, Franks KM, Schaefer AT, Fleischmann A (2016) Massive normalization of olfactory bulb output in mice with a "monoclonal nose." eLife 5:e16335. CrossRef

Rosselli-Austin L, Williams J (1990) Enriched neonatal odor exposure leads to increased numbers of olfactory bulb mitral and granule cells. Dev Brain Res 51:135-137. Medline

Saghatelyan A, Roux P, Migliore M, Rochefort C, Desmaisons D, Charneau P, Shepherd GM, Lledo P-M (2005) Activity-dependent adjustments of the inhibitory network in the olfactory bulb following early postnatal deprivation. Neuron 46:103-116. CrossRef Medline

Todrank J, Heth G, Restrepo D (2011) Effects of in utero odorant exposure on neuroanatomical development of the olfactory bulb and odour preferences. Proc R Soc B Biol Sci 278:1949-1955. CrossRef Medline

Treloar HB, Feinstein P, Mombaerts P, Greer CA (2002) Specificity of glomerular targeting by olfactory sensory axons. J Neurosci 22: 2469-2477. Medline

Vassar R, Chao SK, Sitcheran R, Nuñez JM, Vosshall LB, Axel R (1994) Topographic organization of sensory projections to the olfactory bulb. Cell 79:981-991. Medline

Wachowiak M, Cohen LB (2001) Representation of odorants by receptor neuron input to the mouse olfactory bulb. Neuron 32:723735. Medline

Wachowiak M, Cohen LB (2003) Correspondence between odorantevoked patterns of receptor neuron input and intrinsic optical 
signals in the mouse olfactory bulb. J Neurophysiol 89:1623-1639. CrossRef Medline

Wachowiak M, Economo MN, Díaz-Quesada M, Brunert D, Wesson DW, White JA, Rothermel M (2013) Optical dissection of odor information processing in vivo using GCaMPs expressed in specified cell types of the olfactory bulb. J Neurosci 33:5285-5300. CrossRef Medline

Wilson DA, Sullivan RM, Leon M (1985) Odor familiarity alters mitral cell response in the olfactory bulb of neonatal rats. Brain Res 354:314-317. Medline
Wilson DA, Sullivan RM, Leon M (1987) Single-unit analysis of postnatal olfactory learning: modified olfactory bulb output response patterns to learned attractive odors. J Neurosci 7:3154-3162. Medline

Woo CC, Coopersmith R, Leon M (1987) Localized changes in olfactory bulb morphology associated with early olfactory learning. J Comp Neur 263:113-125. CrossRef Medline

Woo CC, Hingco EE, Taylor GE, Leon M (2006) Exposure to a broad range of odorants decreases cell mortality in the olfactory bulb. Neuroreport 17:817. CrossRef Medline 